\title{
Examining the Intersection of Gender and Age in Victim Blaming
}

Jerin Lee

West Virginia University, jl0147@mix.wvu.edu

Follow this and additional works at: https://researchrepository.wvu.edu/etd

Part of the Social Psychology Commons

\section{Recommended Citation}

Lee, Jerin, "Examining the Intersection of Gender and Age in Victim Blaming" (2019). Graduate Theses, Dissertations, and Problem Reports. 7439.

https://researchrepository.wvu.edu/etd/7439

This Thesis is protected by copyright and/or related rights. It has been brought to you by the The Research Repository @ WVU with permission from the rights-holder(s). You are free to use this Thesis in any way that is permitted by the copyright and related rights legislation that applies to your use. For other uses you must obtain permission from the rights-holder(s) directly, unless additional rights are indicated by a Creative Commons license in the record and/ or on the work itself. This Thesis has been accepted for inclusion in WVU Graduate Theses, Dissertations, and Problem Reports collection by an authorized administrator of The Research Repository @ WVU. For more information, please contact researchrepository@mail.wvu.edu. 
Examining the Intersection of Gender and Age in Victim Blaming

Jerin Lee, M.S.

Thesis submitted

to the Eberly College of Arts and Sciences

at West Virginia University

in partial fulfilment of the requirements for the degree of

Master of Science in

Psychology

Natalie Shook, Ph.D., Chair

Amy Fiske, Ph.D.

Elisa Krackow, Ph.D.

Julie Patrick, Ph.D.

Department of Psychology

Morgantown, West Virginia

2019

Keywords: Sexism, Ageism, Victim Blaming, Crimes

Copyright 2019 Jerin Lee 


\begin{abstract}
Examining the Intersection of Gender and Age in Victim Blaming
\end{abstract}

Jerin Lee

Victim blaming refers to an attributional tendency in which some level of responsibility for a negative outcome is placed on victims (Maes, 1994). Many victims of crimes face stigmatization in the form of blame from friends, acquaintances, the criminal justice system, media, strangers, and even perpetrators of the crimes themselves (e.g., Cross, Parker, \& Sansom, 2019; Gordon \& Riger, 1991). Victim characteristics, type of crime, and observer characteristics all influence victim blaming tendencies. However, no studies to date have tested whether these factors in combination elicit differential reactions to victims of crimes. The present research tested how the intersection of gender (man vs. woman) and age (younger vs. older) affect attributional evaluations of victims across a variety of crime vignettes in younger and older adult participants. Study 1 was conducted among a sample of young adult participants to test how manipulations of victim characteristics (man or woman; younger or older) influence attributions about the victims and perpetrators across four crimes (i.e., aggravated assault, sexual assault, pickpocketing, and credit card scam). Study 2 was conducted among a sample of older adults to not only replicate the first study, but also examine how patterns of victim blaming may differ based on participants' age. Results across the two studies demonstrated that there are stereotypes regarding who is expected to be the mostly likely victim of aggravated assault (i.e., younger man), sexual assault (i.e., younger woman), and a credit card scam (i.e., older woman). Patterns of results revealed that participants did not attribute the most blame to victims who were considered to be the most likely victim of each crime. There was also a general pattern where men, compared to women participants, attributed more blame to victims of pickpocketing. Additionally, older men blamed victims of sexual assault more than older women. There was no support for the defensive attribution hypothesis, as sharing similar identities (i.e., gender and age) with victims did not reduce participants' victim blaming tendencies. Lastly, victim blaming did not significantly differ based on participant's age. Overall, both studies provided support for the significant and variable roles of victim characteristics, type of crime, and participant characteristics in contributing to victim blaming tendencies, even after controlling for multiple crime characteristics (e.g., severity of the crime) and individual differences about justice. 
Table of Contents

Examining the Intersection of Gender and Age in Victim Blaming ..................................... 1

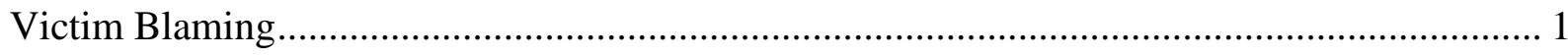

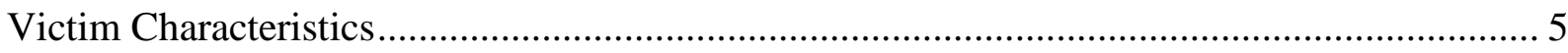

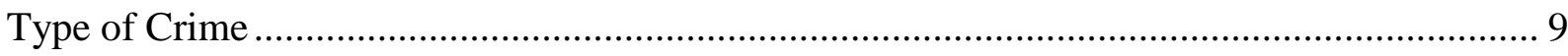

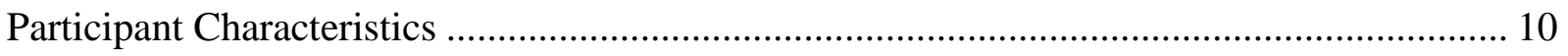

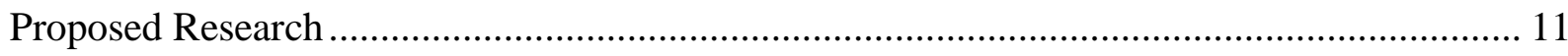

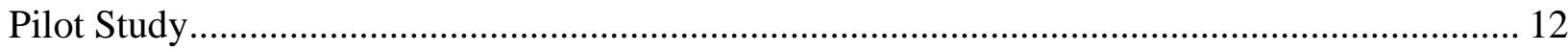

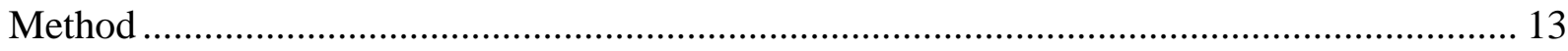

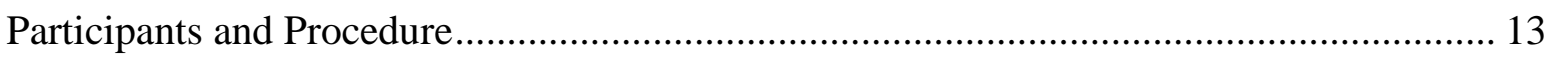

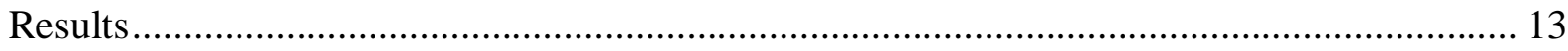

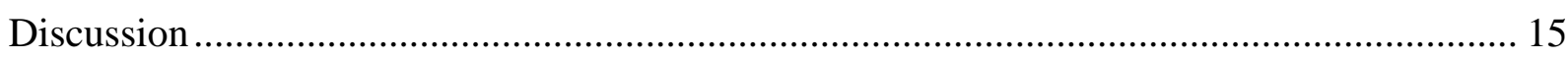

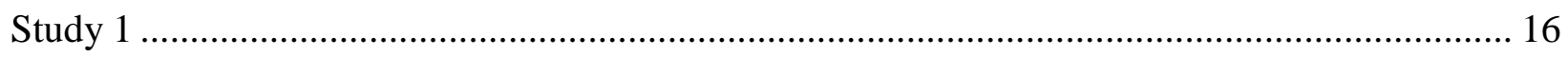

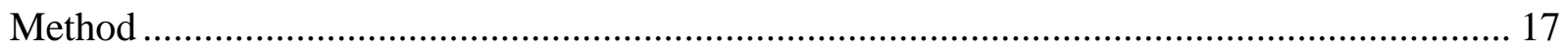

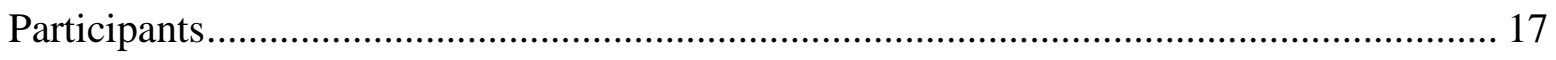

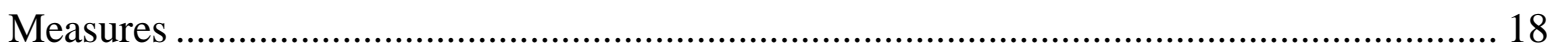

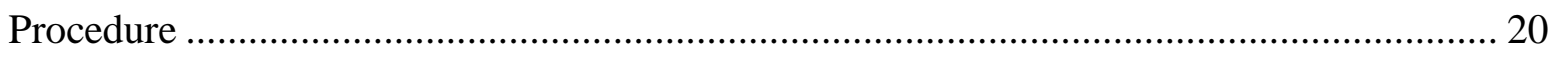

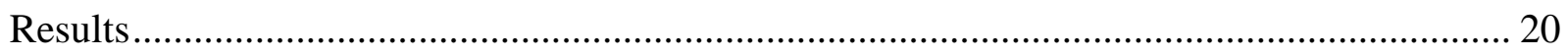

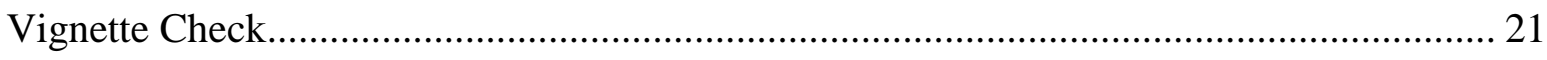

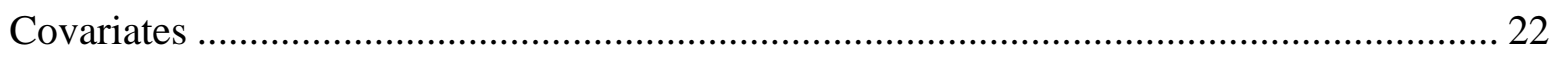

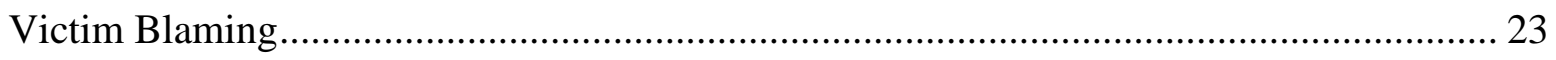

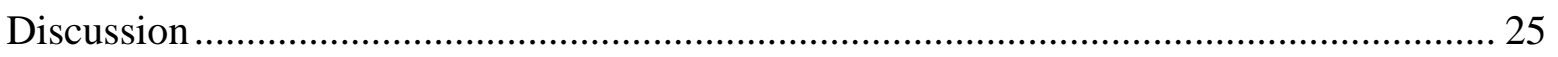

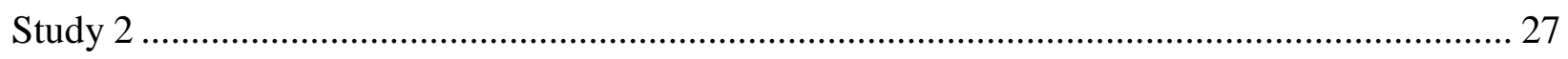

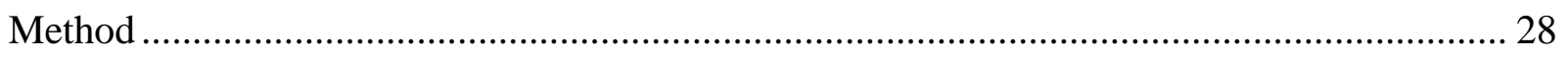

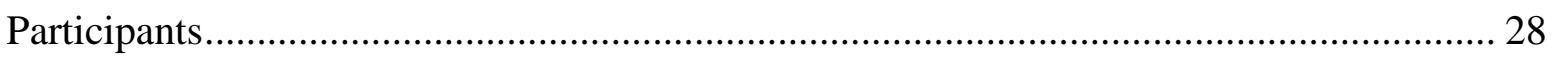

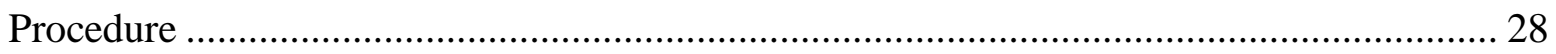

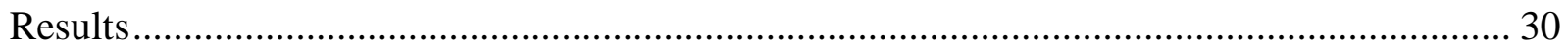

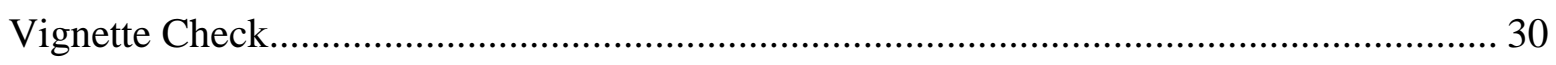

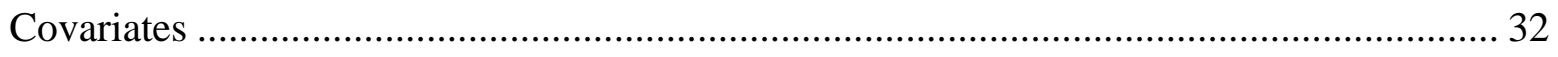

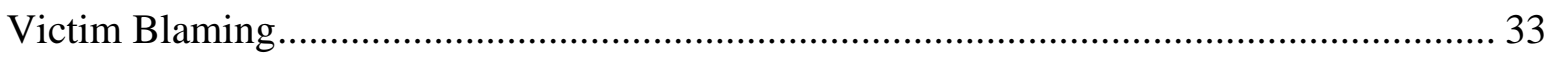

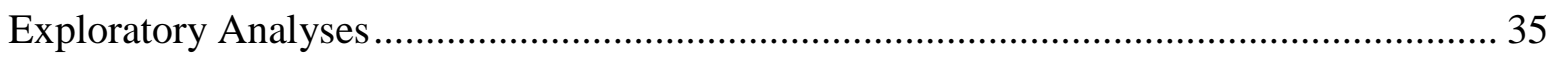

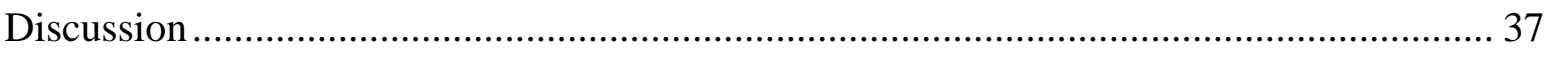

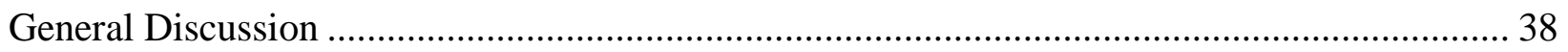




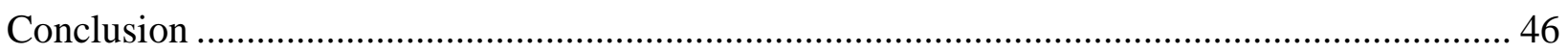

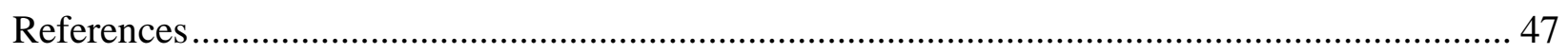

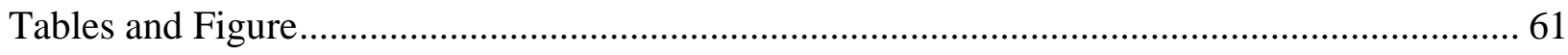

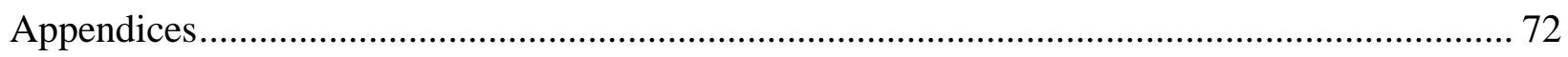


Examining the Intersection of Gender and Age in Victim Blaming

There are profound emotional and psychological consequences associated with the experience of a crime (e.g., rape, financial fraud; Mason \& Lodrick, 2013; Quraisha, 2019). Unfortunately, many victims of crimes face stigmatization in the form of blame from friends, acquaintances, the criminal justice system, media, strangers, and even perpetrators of the crimes themselves (Cross, 2015; Cross, Parker, \& Sansom, 2019; Gordon \& Riger, 1991; Henning, Jones, \& Holdford, 2005; Meyer, 2016). In order to reduce the stigmatization associated with victimization, it is imperative to first understand the circumstances under which victim blaming occurs. Thus, the goal of the proposed research was to investigate how victim characteristics, the type of crime, and observer characteristics influence and elicit differential reactions to victims of crimes.

\section{Victim Blaming}

In general, victim blaming refers to an attributional tendency in which some level of responsibility for a negative outcome is placed on victims (Maes, 1994). Early theorists have posited that attribution of responsibility to victims exists on a continuum from being wholly innocent to fully responsible for the act of crime, maltreatment, or misfortune (von Hentig, 1941, 1948; Mendelsohn, 1976, 1982; Schafer, 1968). For example, victims who did not contribute to the act (e.g., victims of natural disasters) should bear no responsibility for their victimization (von Hentig, 1941, 1948; Mendelsohn, 1976, 1982; Schafer, 1968), whereas victims considered to be precipitative or provocative (e.g., those who wear certain clothes, those who provoke perpetrators; Mendelsohn, 1976, 1982), as well as highly guilty victims (e.g., a robber who is murdered) will likely be attributed high levels of victim responsibility. However, the wholly 
innocent victim is quite rare (Eigenberg \& Garland, 2008), and there remains a tendency to blame individuals even when the victim's role in the victimization is unclear.

Studies have demonstrated that individuals are blamed for being homeless or poor (Phelan, Link, Moore, \& Stueve, 1997; Wright, 1993), for having poor health (Crawford, 1977), and especially for being the victims of crimes (Cross, 2015; Grubb \& Turner, 2012; Pagliaro et al., 2018). In fact, there is an overwhelming amount of research regarding the tendency to blame victims of crime, wherein victim blaming has been demonstrated by participants' tendencies to attribute any amount of responsibility (Gold, Landerman, \& Bullock, 1977; Niemi \& Young, 2016), blame (Niemi \& Young, 2016; Valor-Segura et al., 2011; Weber, Ziegele, \& Schnauber, 2013), and/or fault (Abrams et al., 2003; Qi et al., 2016) to victims of crimes. Conversely, participants vary in their tendency to attribute full responsibility, blame, and/or fault to perpetrators of crime (e.g., Niemi \& Young, 2016). Others have assessed victim blaming by asking for participants' attitudes about perpetrator persecution (Valor-Segura, Expósito, \& Moya, 2011) and rape myth acceptance (Hayes, Lorenz, \& Bell, 2013). Despite a lack of consensus on a singular measure of victim blaming, it is apparent that the tendency to attribute some level of responsibility to victims remains today.

Victim blaming is widely understood within the framework of attribution theory. Attribution represents the process by which individuals attempt to explain their own behavior or the behavior of others (Buss, 1978; Kelley, 1973). People can make either internal attributions, where causal explanations for behavior come from an individual, or external attributions, where causal explanations are located in environmental factors (Heider, 1958). Attributions are subject to biases, errors, and the influence of other cognitive processes. For example, researchers have posited that attributional processes are inextricably associated with stereotyping, or the way we 
perceive members of different groups (Power, Murphy, \& Coover, 1996; Reyna, 2000; Stephan, 1977). Consistent with this notion, Power and colleagues (1996) found that when participants were exposed to negative stereotypes about African Americans, they made more internal or dispositional attributions of responsibility about an African American male's unfortunate circumstances. In contrast, they found that positive counter-stereotypic priming increased external or situational attributions of responsibility regarding the plight of an African American individual. They also found similar patterns when priming participants with stereotypic and counter-stereotypic portrayals of a female. Specifically, stereotype consistent priming decreased perceived credibility, whereas counter-stereotypical priming increased the perceived credibility of females. Such findings endorse the link between stereotypes and attributions of responsibility to victims.

Importantly, there are two attributional biases that explain the tendency to victim blame: belief in a just world and defensive attributions. The just world belief is predicated on the idea that people deserve what happens to them - good things happen to good people, and bad things happen to bad people (Lerner, 1980). This belief provides a psychological buffer against the harsh and variable circumstances of life, enabling individuals to feel as though they have personal control over their own destiny (Furnham, 2003). Belief in a just world can be threatened when individuals learn about someone who has been victimized. To protect their belief in justice, a common response is to justify the victimization by believing that the victim must have done something to bring about their misfortune (e.g., victim is a bad person; victim engaged in reckless behavior). This justification essentially blames the victim for their victimization, maintaining one's belief in a just world and reducing concerns that one could similarly be a victim. Consistent with this theory, there is empirical evidence linking greater belief in a just 
world to negative reactions toward victimized or disadvantaged individuals (e.g., rape victims, cancer patients, patients with AIDS; Braman \& Lambert, 2001; see Furnham, 2003 for a review; Glennon \& Joseph, 1993; Sakall1-Uğurlu, Yalçın, \& Glick, 2007). Existing research indicates there are individual differences in belief in a just world, and that these differences are linked with variability in victim blaming.

The second explanation for victim blaming centers around defensive attributions. According to the defensive attribution hypothesis, attributional errors can be influenced by an individual's perceived similarity to a victim and perceived likelihood of a similar misfortune happening to them in the future (Cann, Calhoun, \& Selby, 1979; Chaikin and Darley, 1973; Grubb \& Turner, 2012; Kanekar \& Vaz, 1988; Muller, Caldwell, \& Hunter, 1994; Shaver, 1970; Thornton, Ryckman, \& Robbins, 1982). Observers' victim blaming tendencies increase (decrease) when perceived similarity to a victim is low (high), which serves as a defense mechanism (Grubb \& Turner, 2012). The idea that events can happen by chance or by accident is discomforting. Thus, for those who perceive less similarity to a victim, victim blaming is a defense mechanism because it protects themselves from the discomfort associated with the idea that they too could experience a similar fate. For those who perceive more similarity to a victim, the decrease in victim blaming tendencies serves to protect observers from being blamed if they were to experience a similar misfortune in the future (Grubb \& Harrower, 2008). Empirical evidence supports the link between defensive attributions and victim blaming. For example, many studies have found that male participants, compared to female participants, are more likely to attribute blame and responsibility to female rape victims (Calhoun, Selby, \& Warring, 1976; Kleinke \& Meyer, 1990; Luginbuhl \& Mullin, 1981). Additionally, perceived similarity to a rape victim was related to less victim blaming (Fulero \& DeLara, 1976). Thus, the defensive 
attribution hypothesis represents a framework for understanding why variability in victim blaming exists.

Of note, belief in a just world and defensive attribution are both related to understanding the circumstances under which individuals allocate responsibility to actors within a scenario. This commonality may suggest that these theories represent complementary, as opposed to discrete, concepts (Muller et al., 1994; Shaver, 1970). Taken together, both theories represent important frameworks for understanding individual differences in victim blaming in the proposed research. In unpacking this variability, findings from studies have consistently demonstrated the critical influence of victim characteristics, situational or external factors, and observer characteristics on victim blaming attributions (van der Bruggen \& Grubb, 2014; Calhoun, Selby, \& Keller, 1978; Grubb \& Harrower, 2008).

\section{Victim Characteristics}

Variability in victim blaming can in part be explained by differing characteristics of victims. Decades of research have demonstrated that judgments of victims differ based on a wide range of demographic, personality, and behavioral factors, such as race, class, sexual orientation, level of extraversion, and stereotypicality (Anderson, 1999; Capezza \& Arriaga, 2008; Davies, Pollard, \& Archer, 2001; Donovan, 2007; Gerdes, Dammann, \& Heilig, 1988; Sleath \& Bull, 2010; Thornton \& Ryckman, 1983; Weber et al., 2013; Whatley, 1996). For example, participants were found to attribute more blame to rape victims who were gay men and heterosexual women than lesbians or heterosexual men (Wakelin \& Long, 2003). A recent review of the literature demonstrated that women rape victims who violate traditional gender norms are attributed more blame than women who do not (Grubb \& Turner, 2012). These results highlight the impactful role victim characteristics play in negative reactions to victims. 
Of studies that have looked at victim characteristics, a considerable amount of research has found that victim gender plays a critical role in attributions of blame. One of the most robust and consistent patterns revealed from research on sexual violence is that female rape victims are blamed more than male rape victims (Grubb \& Harrower, 2008; Howard, 1984; Schneider, Ee, \& Aronson, 1994). Conversely, male victims of domestic violence in heterosexual relationships are attributed more blame than female victims (Terrance, Plumm, \& Thomas, 2011). Taken together, it is apparent that the gender of the victim plays a critical role in influencing attributions of blame.

One problem in studying the role of gender in victim blaming research is that the perpetrator is often assigned a gender as well. This becomes problematic as participant evaluations could then be guided by other underlying attitudes (e.g., homophobic attitudes), which may confound existing findings on the role of gender in victim blaming. For example, Anderson (2004) found that homophobic attitudes were significantly correlated with attributions of blame to male rape victims. Relatedly, Davies et al. (2001) found that male participants blamed gay male stranger rape victims more than female victims. Despite such results, much of the extant research on victim blaming has continued to assign the offenders of crime a gender within vignettes. One practical solution would be to assess for victim blaming attitudes using vignettes that manipulate the victim' gender while concealing the perpetrator's gender. Doing so would expand the current literature by isolating and clarifying the role of victim gender on attributional tendencies.

Some research has also started to examine the effect of victim age on victim blaming concepts (Callan, Dawtry, \& Olson, 2012; Rogers, Josey, \& Davies, 2007; Strömwall, Alfredsson, \& Landstrom, 2013). For example, Strömwall and colleagues (2013) found that 
younger (20 years) rape victims, compared to middle-aged (46 years) victims, were assigned more blame. However, it is important to note that in their study, there was no examination of a victim beyond the age of 46 years, and the characteristics of the perpetrator were held constant (an unknown man in his 30s). Thus, as discussed previously, it is unclear whether similar patterns of results would emerge had the gender of the perpetrator been concealed. In another study, when researchers (Callan, Dawtry, \& Olson, 2012) examined the impact of an innocent victim's age on perceptions of injustice and punishment, they found that the suffering of an older (74 years) compared to a younger adult (18 years) was perceived as less unfair, and that participants punished perpetrators less when the innocent victim was younger. However, these researchers did not assess for attributions of blame to the victim in the context of age.

Despite a growing number of studies that demonstrate the impact of victim age, there is a gap in the literature when it comes to systematically manipulating the age of the victim and comparing between different victim age groups (Bruggen \& Grubb, 2014). Across multiple disciplines including psychology, public health, and women's studies, research pertaining to age related biases has traditionally been lacking. Despite increased pressure to consider the intersection of identities (e.g., gender, race/ethnicity, class) in behavioral science research (Cole, 2009; Levy, 1988; Shields, 2008), the role of age remains commonly overlooked. The neglect of age contributes to the implicit and common assumptions central to American culture (e.g., middle-class standing, heterosexuality, White race) that discredit the differential experiences of diverse individuals (Cole, 2009; Sue, 2004). Indeed, it is unsurprising that psychological studies on victim blaming have mostly consisted of young adult participants and have centered around young adult victims or children (Back \& Lips, 1998; Davies, Rogers, \& Whitelegg, 2009). 
This is a significant shortcoming in the literature given that experiences of victimization are not exclusive to young or middle-aged individuals. For example, although younger women, compared to older women, have been found to be disproportionately affected by sexual assault (Morgan \& Mason, 2014), this does not preclude older women from experiencing sexual violence (Del Bove, Stermac, \& Bainbridge, 2005). Moreover, older adults are considered to be particularly susceptible to consumer and financial fraud victimization (Mears, Reisig, Scaggs, \& Holtfreter, 2016), as well as abuse and neglect (Cooper, Selwood, \& Livingston, 2008; Lachs \& Pillemer, 2004). Despite scholarship acknowledging that victimization occurs among older adults, limited effort has been made to understand how victims' age (specifically, older age) may influence victim blaming, leading to the inadvertent exclusion of research on older individuals in this area.

When considering the intersection of age and gender, it is important to note that relevance of the double jeopardy hypothesis. Essentially, it is thought that the interplay of sexism and ageism puts older women at a disadvantage compared to other age and gender groups (Krekula, 2007). However, conceptualizing older women's experiences as a double jeopardy is stigmatizing in itself, as it minimizes the differential experiences of older women across various contexts. Interestingly, despite evidence supporting a double jeopardy effect for older women, there may be a potential advantage in that the intersection of age and gender may construct a new form of marginalization (Krekula, 2007), or weaken and neutralize the effects of each other. For example, in the context of victim-blaming, the double jeopardy effect may not apply to older women, as evident in criminologist Christie's (1986) conceptualization of the 'ideal' victim being centered around a "little old lady." However, it is unclear whether older women may indeed be attributed less blame across all types of crimes. 
Taken all together, it is apparent that gender and age represent important individual factors that function differentially in the attribution of blame. The current research aimed to bridge the gap in the existing literature by systematically examining the ways in which the intersection of these victim characteristics contributes to the attribution of blame.

\section{Type of Crime}

External or situational factors such as societal attributes (e.g., culture), discrimination, chance, and the behavior of others are strongly associated with attributions of blame (Frazier, 1990; Grubb \& Harrower, 2008; Henning, Jones, \& Holdford, 2005; Johnson, Mullick, \& Mulford, 2002; Mulford, Lee, \& Sapp, 1996; Shaver, 1970). Within the context of crimes, there is overwhelming evidence suggesting that the type of crime itself elicits different responses to victims. For example, Bieneck and Krahé (2011) found that female victims of rape were blamed more than female victims of robbery. Furthermore, there is significant evidence suggesting that different "types" of rape (e.g., acquaintance and stranger rape) are associated with different reactions from observers. In general, participants tend to attribute more responsibility to victims of acquaintance rape as opposed to stranger rape (e.g., Grubb \& Harrower, 2008). However, given that the literature on victim blaming predominantly focuses on crimes of sexual violence (i.e., rape) as well as young female victims, it is unclear how patterns of attributional blame that have been found among crimes of sexual violence would apply to other crimes.

Furthermore, it is difficult to consolidate the findings of the current literature on the roles of gender and age in victim blaming given the wide range of vignettes presented in the studies. There is an inability to standardize findings across studies given that vignettes varied in the degree to which information about the victims' characteristics and situational context were presented. In order to address this problem, the present study utilized vignettes that not only 
depict various crimes, but also provide similar amounts of information across crimes. It is apparent that victims' characteristics play an important role in shaping attributions of blame; however, given that most of the research has focused on crimes of rape, it is important to explore how the influence of these victim characteristics may vary across different crimes.

\section{Participant Characteristics}

In addition to the critical roles of victim characteristics and situational context, it has been well documented that observer characteristics (e.g., political ideology, gender) strongly influence attitudes toward victims of crime (Anderson, 2004; Franklin \& Menaker, 2015; Spaccatini, Pacilli, Giovannelli, Roccato, \& Penone, 2019). For example, male participants blame female rape victims more than female participants (Davies et al., 2009; Donovan, 2007; Kelly, 2010). Intimate violence research has yielded more mixed results. Although findings from some studies revealed that male university students were more likely to attribute blame to a female victim of domestic violence than female students (Bryant \& Spencer, 2003), other researchers have found that female students blamed female victims of intimate violence more than male students (Kristiansen \& Guiliette, 1990). Such mixed findings may in part be explained using the framework of defensive attribution, in that greater similarity to personal aspects play a significant role in less victim blaming (Shaver, 1970). For example, findings from studies on the blaming of rape victims have consistently provided support for this theory in that participants with greater perceived similarity to a victim of rape were less likely to attribute blame to the victim (e.g., Bell, Kuriloff, \& Lottes, 1994; Fulero \& DeLara, 1976; Grubb \& Harrower, 2008). Specifically, Bell and colleagues (1994) found that women, compared to men, participants perceived more similarity to a female rape victim, and thus blamed the victim less. 
Despite mixed findings, it is apparent from the extant literature that the gender of the participant may significantly influence attributions of blame to a victim.

One significant limitation regarding the research linking participant characteristics to victim blaming is that studies have primarily utilized samples of young to middle aged adults, making all aforementioned findings difficult to generalize to older adult populations. To the researcher's knowledge, only one study to date has attempted to examine how victim blaming varies across age groups. Adams-Price and colleagues (2004) found that older adults blamed victims more than young or middle-aged adults. Thus, there is a need to determine the extent to which victim blaming patterns found in younger adults apply to older adults. For example, if perceived similarity to the victim represents an important determinant of attributions of blame, then a similar victim blaming pattern should emerge across gender and age groups based on the characteristics of the target in the vignette. However, there has yet to be an examination of how victim blaming may vary depending on victim characteristics, type of crime, and participant gender among older adults.

\section{Proposed Research}

Few studies have examined the extent to which victim characteristics, crime type, and observer characteristics elicit differential reactions to victims of crimes. The purpose of the proposed research was to test how the intersection of gender (woman vs. man) and age (young vs. old) affect attributional evaluations of victims across a variety of crime vignettes. The first study was conducted among a sample of young adult participants to examine how manipulations of victim characteristics (woman or man; young or old), as well as participant gender influence attitudes toward victims and perpetrators across four crimes. The second study was conducted 
among a sample of older adults to not only replicate the first study, but also examine how patterns may differ based on participant characteristics.

\section{Pilot Study}

A pilot study was conducted to develop and identify vignettes to use in Study 1 and Study 2. Vignettes were modeled after previous victim blaming studies (Anderson, 2004; Back \& Lips, 1998; Sleath \& Bull, 2010; Strömwall et al., 2013; Wakelin \& Long, 2003), and were written in the form of brief police reports. As discussed previously, individuals are more likely to make internal attributions (e.g., attributions of responsibility) when encountering situations that are consistent with stereotypical beliefs. Thus, the vignettes were developed with the intention of tapping into stereotypical beliefs of who may be considered the most likely victim of a crime. For example, given that research, discourse, and literature regarding sexual assault primarily focuses on younger women as victims, it would be expected that participants would consider a younger woman as the most likely victim of a sexual assault crime. Potentially, attributions of blame may be greater for victims that match the stereotypical victim of a crime. Thus, the goal was to find four crimes that are associated with stereotypical victims that mapped on to the manipulated victim characteristics (i.e., young man, young woman, old man, old woman).

The pilot study tested the extent to which nine crime vignettes (i.e., sexual assault, credit card scam, pickpocketing, aggravated assault, intimate partner violence, robbery, car-onpedestrian collision, car-on-car collision, and mugging) aligned with participants' beliefs of stereotypical victims. The victims' gender and age were concealed, so that basic reactions to the vignettes, unaffected by victim characteristics, could be assessed. 


\section{Method}

\section{Participants and Procedure}

Participants were recruited from the West Virginia University Department of Psychology's undergraduate subject pool, using the online SONA system. In this pilot study, nine different crime vignettes were tested (see Appendix A). Participants $(N=69 ; 55$ women; $M_{\text {age }}=19.41$ years, $S D=1.90 ; 84.3 \%$ White/Caucasian, $5.8 \%$ multiethnoracial, $4.3 \%$ Asian, 1.4\% Hispanic/Latinx, 1.4\% African American/Black, 1.4\% Native American) completed an online study. After electronically agreeing to be part of the study, participants were shown each of the nine vignettes in a random order. After each crime, they were asked to assess characteristics of the crime (e.g., likelihood, severity, realistic), the victim (e.g., extent to which victim was emotionally or physically harmed, extent to which the victim was responsible for the incident), and the perpetrator (e.g., extent to which the perpetrator was responsible for the incident, extent to which the perpetrator should be punished). Then, participants were asked to indicate who (a younger man, younger woman, older man, or older woman) would be the most likely victim in each crime.

\section{Results}

A Pearson Chi-Square analysis was conducted to determine whether the most likely victim (younger man, younger woman, older man, or older woman) differed by crime. The comparison across the nine crimes was significant, $\chi^{2}(24)=410.95, p<.001$ (see Table 1 ). Crosstabulations regarding the frequency of victim selection for each crime revealed six crimes for which a significant portion of the participants selected a particular target. Specifically, $68 \%$ of all participants selected the younger man as the most likely victim of aggravated assault; $95.7 \%$ of all participants selected the younger woman as the most likely victim of sexual assault; 
$85.5 \%$ of all participants selected the younger woman as the most likely victim of intimate partner violence; $42 \%$ of all participants selected the older man as the most likely victim of pickpocketing; $55.1 \%$ of all participants selected the older woman as the most likely victim of a credit card scam; and $55.1 \%$ of all participants selected the older woman as the victim of robbery. For the remaining three crimes, there was not a clear victim that the majority of participants selected. Of note, while it may have been ideal if the proportion of participants who selected the older man were similar to those of the other target victims, it is acknowledged there was variability regarding the strength of the "most likely victim" stereotype across all crimes. As such, given the measures taken in the pilot study to test a comprehensive set of crimes (i.e., researching crimes, consulting undergraduates), it may be possible that existing stereotypes of an older man victim do not align with a particular type of crime as strongly as the other target victims.

Subsequent Pearson Chi-Square Goodness-of-Fit analyses revealed that selection of the most likely victim of aggravated assault was not equally distributed, $\chi^{2}(3)=71.00, p<.001$. Analyses also demonstrated that selection of the most likely victim of pickpocketing was not equally distributed, $\chi^{2}(3)=12.68, p<.01$. These analyses, combined with the initial visual inspection of the crosstabulations, made it apparent that the younger man and the older man were considered the stereotypical victims of aggravated assault and pickpocketing, respectively.

To determine the main vignettes for the younger woman and older woman, odds ratios were computed. The odds of participants choosing the younger woman as the victim were 3.73 times higher for the sexual assault vignette than the IPV vignette, $\chi^{2}(1)=4.16, p<.05$. Thus, the sexual assault vignette, rather than the intimate partner violence vignette, was determined to be the vignette that most aligned with a young woman victim. However, odd ratio computations 
revealed that the odds of participants choosing the older woman as the victim were comparable for both the credit card and robbery vignettes, $\chi^{2}(1)=0.00, p=1.00$.

To determine whether the credit card scam or the robbery vignette would be chosen as a main vignette for the older woman victim, a one-way repeated measures analysis of variance (ANOVA) was conducted to compare the effect of crime type (6 different crimes) on each of the eleven crime characteristics (e.g., How severe is this incident?, To what extent is the victim responsible for what happened?). All analyses revealed a significant effect of crime type on perceived characteristics of the crime, $p$ s $<.01$. Post-hoc analyses were conducted to determine the extent to which characteristics of the credit card scam or robbery crime were statistically comparable with the characteristics of the other three main vignettes (see Table 2). Comparisons of the means indicated that the credit card scam shared statistically comparable means for nine of the eleven perceived characteristics with at least one other main vignette (i.e., sexual assault, pickpocketing, aggravated assault), whereas the robbery crime shared statistically comparable means for only three of the eleven perceived characteristics with at least one other main vignette. Thus, the credit card scam was selected, instead of the robbery vignette.

\section{Discussion}

Based on the analyses of the pilot data, four vignettes successfully aligned with stereotypical beliefs of who may be considered the most likely victim of a crime. Comparing the frequencies of victim selection for each type of crime, it was apparent that participants were most likely to select the younger man as a victim of aggravated assault and an older man as a victim of pickpocketing. Given that crimes that aligned with the younger woman and older woman were not as apparent, computing the odds ratio provided greater insight into a pattern where the odds of participants choosing the younger woman as the victim were 3.73 times higher for the sexual 
assault vignette than the intimate partner violence vignette. Odds ratio analysis revealed that the odds of participants choosing the older woman as the victim of the credit card vignette were comparable to the odds of participants choosing the older woman as the victim of the robbery vignette. Thus, post-hoc comparisons of participants' ratings of each crime revealed that the credit card vignette, rather than the robbery vignette, was perceived as sharing more similar attributes to the three vignettes associated with the younger man, younger woman, and older man. Taking into consideration both the response patterns in selection of the most likely victim and consistency of crimes across the eleven crime characteristics, the final vignette set for Study 1 and Study 2 included the aggravated assault, sexual assault, pickpocketing, and credit card scam crimes (see Appendix B).

\section{Study 1}

The purpose of Study 1 was to test the effect of victim characteristics (i.e., gender and age) and participant characteristics (i.e., gender) on attributions of blame across four crimes among a young adult sample. Consistent with attribution theory, it was hypothesized that there would be a main effect based on victim characteristics in that the stereotypical victim for each crime would be attributed the most blame. Furthermore, it was hypothesized that younger adults would attribute less blame to younger adult victims who are the same gender as them. Specifically, Study 1 addressed six hypotheses:

Hypothesis 1: For the aggravated assault vignette, participants will attribute the most blame to the younger man victim.

Hypothesis 2: For the sexual assault vignette, participants will attribute the most blame to the younger woman victim. 
Hypothesis 3: For the pickpocketing vignette, participants will attribute the most blame to the older man victim.

Hypothesis 4: For the credit card scam vignette, participants will attribute the most blame to the older woman victim.

Hypothesis 5: For the aggravated assault vignette, participants who are men will attribute less blame to the younger man victim than participants who are women.

Hypothesis 6: For the sexual assault vignette, participants who are women will attribute less blame to the younger woman victim than participants who are men.

\section{Method}

\section{Participants}

Based on an a priori power analysis using G*Power, version 3.1 (Faul, Erdfelder, Lang, \& Buchner, 2007), it was determined that a minimum of 277 participants would be needed to detect a small-medium effect size with $\alpha=.05$ and power $=.80$ with a 4 X 2 factorial analysis of covariance (ANCOVA) with two between-subject factors (target victim and participant gender). A total of 417 participants were recruited from Amazon's Mechanical Turk (MTurk), an online survey platform that allows researchers to pay individuals for participating in online research. Inclusion/exclusion criteria consisted of: 1) age between 18 years and 34 years old and 2) US residence. The age range was selected based on previous work that examined victim blaming in a young adult population (Adams-Price et al., 2004). Eighty participants were excluded from the analyses based on exclusion criteria (e.g., stated age did not align with date of birth).

Additionally, given that the purpose of the study sought to examine the influence of gender (i.e., man or woman) on victim blaming, two participants who did not identify as a man or woman were excluded from the analyses. This resulted in a final sample of 352 younger adults (50.9\% 
women; $M_{\mathrm{age}}=28.64$ years, $\mathrm{SD}=4.03$, range: $\left.18-34\right)$. Participants were $63.4 \%$ Caucasian/White, 15.1\% African American/Black, 8.8\% Hispanic/Latinx, 6.0\% multiethnoracial, 5.7\% Asian, $0.6 \%$ Native American, and $0.6 \%$ who identified as "Other."

\section{Measures}

Vignettes. Four crime vignettes (see Appendix B) developed from the pilot study were used. The gender and age of the victim in the vignettes were manipulated. There were four potential combinations for vignette target victims (i.e., younger man, younger woman, older man, older woman). Each target victim was randomly paired with one of the four crime vignettes. Participants saw each target victim and each crime once and were randomly assigned to the combinations of crime and target victims. The vignettes were presented in a random order.

Attributions of blame. To assess victim blaming, participants indicated their responses across a 7-point scale ranging from 1 (Not at all) to 7 (Completely/Totally) to the following four items: "To what extent was the victim responsible for what happened?", "How much was the incident the victim's fault?", "To what extent did the victim bring this upon him/herself?", and "To what extent did the victim act carelessly?". A composite score was created by taking the average score of the four items, with higher scores indicating greater blame. In the present sample, the victim blaming measures demonstrated good reliability for all four crimes: sexual assault (Cronbach's alpha $=.95)$; aggravated assault (Cronbach's alpha $=.94)$; credit card scam $($ Cronbach's alpha $=.92)$; pickpocketing $($ Cronbach's alpha $=.93)$.

Potential Covariates. To control for confounding variables, the following items and measure were included for use as potential covariates in the analyses (see Appendix C).

Crime characteristics. Several questions assessed general attitudes about the crime (e.g., "How severe is this incident?") and victim (e.g., "To what extent was the victim emotionally 
harmed?"). Participants indicated all responses across 7-point scales that ranged from 1 (Not at all) to 7 (To a great extent).

Belief in a Just World. Participants' belief in a just world was assessed as a potential covariate. The Belief in a Just World Scale (BJWS; Dalbert, Montada, \& Schmitt, 1987) is a 6item self-report measure that assesses the extent to which individuals believe in a just world (i.e., a world which is fair and where people get what they deserve). Participants were asked to respond to items (e.g., "I think basically the world is a just place") on a 6-point scale from 1 (Strongly disagree) to 6 (Strongly agree). The BJWS has been found to demonstrate adequate internal reliability (Cronbach's alpha $=.82$; Dalbert, \& Yamauchi, 1994). A composite variable was computed by averaging the items, such that higher scores indicate great belief in a just world. In the present study, the BJWS demonstrated acceptable reliability (Cronbach's alpha $=.88 ; M=3.46, S D=1.08)$. Given previous research linking greater belief in a just world with more negative reactions to victims (see Furnham, 2003 for a review), the BJWS was included to distinguish whether participants' tendencies to victim blame related specifically to victim characteristics and participant gender, as opposed to their general beliefs in fairness.

Demographic questions. Participants were asked a series of demographic questions (see Appendix D). Items included questions about their gender, age, marital status, ethnicity, strength of political affiliation, religious affiliation, level of education, sexual orientation, size of their hometown, and familiarity/involvement with the four main crimes. Demographic questions were assessed as potential covariates. For ease of interpretation, some demographic variables were dichotomized. Namely, $63.4 \%$ of participants were White (vs. not White), $84.7 \%$ identified as heterosexual (vs. not heterosexual), $45.5 \%$ were married (vs. not married), and $90.6 \%$ identified with a religion (vs. did not identify with a religion). 


\section{Procedure}

Approval for the study was obtained from the Institutional Review Board prior to data collection. Participants were invited to complete an online study through MTurk, and they were compensated \$1.00 for their participation. After electronically agreeing to be part of the study, each participant was shown the four crime vignettes in a randomized order. Each vignette was followed by the attributions of blame questions and the crime characteristics questions in a random order. After the vignettes, participants completed the belief in a just world measure and the demographic questions. Finally, in order to determine whether assumptions about the most likely victim would remain consistent across the pilot sample and the MTurk sample, participants were presented with the original nine pilot study vignettes in a random order, and they were asked to identify who they believed would be the most likely victim of each crime.

\section{Results}

Prior to conducting the primary analyses, data were examined for normality, outliers, and missingness. For measures that had skewness and kurtosis greater than one, log transformations were applied. ${ }^{1}$ Analyses were performed with the transformed and non-transformed variables. However, the patterns of results were similar. As such, analyses with the untransformed data are reported for ease of interpretation. Outliers were identified by examining box plots, and values between 1.5 and 3 times the interquartile range were determined to be outliers $(n=20)$. Analyses were conducted with and without outliers, also resulting in patterns of results that were comparable. Thus, outliers were included in the reported analyses. Lastly, frequency analyses

\footnotetext{
${ }^{1}$ Log transformations were applied to the following variables: victim blaming indices for the sexual assault and credit card scam crimes; severity, seriousness, physical harm, and emotional harm associated with the sexual assault crime; severity, seriousness, and physical harm associated with the aggravated assault crime; physical harm associated with the credit card scam crime; likelihood and physical harm associated with the pickpocketing crime.
} 
indicated that missingness for each measure ranged from $0-0.3 \%$. Missingness was addressed by excluding cases on a pairwise basis.

\section{Vignette Check}

A Pearson Chi-Square analysis was conducted to replicate the pilot study findings regarding whether the most likely victim (younger man, younger woman, older man, or older woman) differed by crime for the younger adult sample. The comparison across the nine crimes was significant, $\chi^{2}(24)=1270.25, p<.001$ (see Table 3 ). Cross tabulations regarding the frequency of victim selection for each crime revealed six crimes for which a significant portion of the participants selected a particular target. Specifically, $63.6 \%$ of all participants selected the younger man as the most likely victim of aggravated assault; $72.2 \%$ of all participants selected the younger woman as the most likely victim of sexual assault; $77.3 \%$ of all participants selected the younger woman as the most likely victim of intimate partner violence; $48.9 \%$ of all participants selected the older woman as the most likely victim of a credit card scam; and $40.1 \%$ of all participants selected the older woman as the victim of robbery. For the remaining four crimes, there was not a clear victim that the majority of participants selected. Overall, these patterns resembled the pilot study results.

Of note, only $29.3 \%$ of all participants selected the older man as the most likely victim of pickpocketing, compared to $42 \%$ of all participants having selected the older man as the most likely victim of pickpocketing in the pilot study. Subsequent Pearson Chi-Square Goodness-ofFit analyses demonstrated that selection of the most likely victim of pickpocketing was equally distributed, $\chi^{2}(3)=3.89, p=.27$. Existing stereotypes of an older man victim may not align with a particular type of crime as strongly as the other target victims. 
Subsequent Pearson Chi-Square Goodness-of-Fit analyses revealed that selection of the most likely victim of aggravated assault was not equally distributed, $\chi^{2}(3)=283.07, p<.001$. This finding, along with the initial visual inspection of the crosstabulations, corroborate results of the pilot study indicating that the younger man is considered the stereotypical victim of aggravated assault. In regard to the crimes for which younger and older women were considered as the stereotypical victim, odds ratio computations revealed that the odds of participants choosing the younger woman as the victim were comparable for both the sexual assault and intimate partner violence vignettes, $\chi^{2}(1)=2.44, p=.12$. The odds of participants choosing the older woman as the victim were 1.43 times higher for the credit card vignette than the robbery vignette, $\chi^{2}(1)=5.53, p<.05$. These findings further support results from the pilot study indicating that the younger woman is considered a stereotypical victim of sexual assault, and that the older woman is considered a stereotypical victim of the credit card scam.

\section{Covariates}

Means and standard deviations for crime characteristics are presented in Table 4. Bivariate correlations were examined to determine which covariates would be included in the primary analyses (see Table 5). In general, demographic characteristics were not significantly associated with victim blaming measures. Of note, a dichotomous marital status variable (i.e., married vs. not) was significantly positively associated with victim blaming across three crimes (i.e., sexual assault, aggravated assault, and pickpocketing), suggesting that married individuals were more likely to blame the victim than those who were not married. ${ }^{2}$ Crime characteristics regarding severity, seriousness, and extent to which the victim was physically and emotionally

\footnotetext{
${ }^{2}$ Given that marital status was measured as a nominal variable, it was dichotomized for ease of interpretation.
} 
harmed were significantly negatively associated with victim blaming measures for the sexual assault and aggravated assault crimes. These crime characteristics were all significantly positively associated with the victim blaming measure for the credit card scam. The extent to which the victim was physically and emotional harmed were significantly positively associated with the victim blaming measure for the pickpocketing crime. Participants' belief in a just world was significantly positively associated with victim blaming across all crimes. Likelihood of the crime and participants' experience (direct or indirect) with the respective crime were generally not significantly associated with victim blaming, so these variables were not included as covariates. Thus, marital status, crime severity, seriousness, the extent to which the victim was physically and emotionally harmed, and belief in a just world were used as covariates.

\section{Victim Blaming}

To determine patterns of victim blaming for the four crimes, the proposed 4 (Victim: Younger Man, Younger Woman, Older Man, or Older Woman) X 2 (Participant Characteristic: Man or Woman) factorial ANCOVA was conducted for each vignette (i.e., four ANCOVAs total). ${ }^{3}$ Victim and Participant Characteristic were entered as between-subjects variables, along with the aforementioned covariates (i.e., marital status, severity, seriousness, physical harm, emotional harm, and belief in a just world). Partial eta-squared $\left(\eta_{\mathrm{p}}{ }^{2}\right)$ was used as a measure of

\footnotetext{
${ }^{3}$ An analysis of variance (ANOVA) was also conducted for each crime without covariates. Patterns of results were similar to those demonstrated by the ANCOVAs, with three exceptions: (1) For the sexual assault crime, there was a significant main effect of gender, but not target victim, on victim blaming $\left(F(1,344)=9.51, p=.002, \eta_{\mathrm{p}}{ }^{2}=.03\right)$. Participants who were men $(M$ $=2.24, S E=.12)$ blamed victims more than participants who were women $(M=1.71, S E=.12, p$ $=.002$ ). (2) For the aggravated assault crime, there was not a significant effect of target victim on victim blaming, $\left(F(3,344)=1.42, p=.24, \eta_{\mathrm{p}}^{2}=.01\right)$. (3) For the aggravated assault crime, decomposition of the significant Victim $\mathrm{x}$ Gender interaction revealed that there was no significant difference in women participant's ratings of victim blaming between the younger man $\operatorname{victim}(M=2.94, S E=.23)$ and older woman victim $(M=2.47, S E=.25, p=.17)$.
} 
effect size according to Cohen's (1969) convention for small $\left(\eta_{\mathrm{p}}{ }^{2}=0.01\right)$, medium $\left(\eta_{\mathrm{p}}{ }^{2}=0.06\right)$, and large effects $\left(\eta_{\mathrm{p}}{ }^{2}=0.14\right)$. Means and standard errors for victim blaming for each crime by target victim and participant gender are presented in Table 6.

Regarding the aggravated assault crime, there was a significant main effect of target victim on victim blaming $\left(F(3,337)=2.89, p=.04, \eta_{\mathrm{p}}{ }^{2}=.03\right)$. Post hoc analyses revealed that participants blamed the younger man victim more than the younger woman or older woman victim $(p s<$.04). Participants also blamed the older man victim more than the older woman victim $(p=.05)$. Participants' rates of victim blaming did not differ between the younger man victim and older man victim $(p=.77)$, the younger woman victim and older man victim ( $p$ $=.08)$, or the younger woman victim and older woman victim $(p=.82)$. There was a significant main effect of participant gender on victim blaming $\left(F(1,337)=9.72, p=.002, \eta_{\mathrm{p}}{ }^{2}=.03\right)$. Participants who were men blamed victims more than participants who were women. These main effects were qualified by a significant Victim x Gender interaction $\left(F(3,337)=3.92, p=.009, \eta_{\mathrm{p}}{ }^{2}\right.$ $=.03$; see Figure 1). The interaction was decomposed, and simple main effects analyses revealed three noteworthy findings. First, participants who were randomized to the older man victim condition for the aggravated assault crime were more likely to blame the older man if the participants themselves were men as opposed to women $(p<.001)$. Second, men participants blamed the older man victim significantly more than the younger woman victim and the older woman victim $(p s \leq .01)$. Finally, women participants blamed the victim more if the victim was a younger man as opposed to an older man or older woman $(p s<.02)$.

For the sexual assault crime, there was a significant main effect of target victim on victim blaming $\left(F(3,337)=2.81, p=.04, \eta_{\mathrm{p}}{ }^{2}=.02\right)$. Post hoc analyses revealed that participants exhibited more victim blaming when the victim was a younger woman or older woman as 
opposed to a younger man $(p s<.05)$. Participants' rates of victim blaming did not differ between the younger man victim and older man victim $(p=.10)$, the younger woman victim and older man victim $(p=.25)$, the younger woman victim and older woman victim $(p=.41)$, or the older man victim and the older woman victim $(p=.73)$. The main effect of participant gender was not significant for victim blaming tendencies $\left(F(1,338)=2.59, p=.11, \eta_{\mathrm{p}}{ }^{2}=.008\right)$. The Victim $\mathrm{x}$ Gender interaction was also not significant for this particular crime $\left(F(3,337)=1.67, p=.17, \eta_{\mathrm{p}}{ }^{2}\right.$ $=.02)$.

Regarding the pickpocketing crime, the main effect of target victim was not significant for victim blaming tendencies $\left(F(3,337)=.26, p=.86, \eta_{\mathrm{p}}^{2}=.002\right)$. However, there was a significant main effect of participant gender on victim blaming $\left(F(1,338)=9.91, p=.002, \eta_{\mathrm{p}}^{2}\right.$ $=.03)$. Participants who were men blamed victims more than participants who were women. The Victim $x$ Gender interaction was not significant for the pickpocketing crime $(F(3,337)=1.18, p$ $\left.=.52, \eta_{\mathrm{p}}^{2}=.01\right)$.

Finally, analyses for the credit card scam crime revealed that the main effects of both target victim $\left(F(3,337)=1.41, p=.24, \eta_{\mathrm{p}}^{2}=.01\right)$ and participant gender $(F(1,337)=.21, p=.65$, $\left.\eta_{\mathrm{p}}{ }^{2}=.001\right)$ were not significant for victim blaming tendencies. The Victim x Gender interaction was also not significant for this specific crime $\left(F(3,337)=1.25, p=.29, \eta_{\mathrm{p}}{ }^{2}=.01\right)$.

\section{Discussion}

The purpose of Study 1 was to determine the extent to which victim characteristics (i.e., gender and age) and participant characteristics (i.e., gender) influenced the victim blaming tendencies of younger adults across four different crimes. A series of four hypotheses posited that there would be a main effect of victim characteristics, such that the stereotypical victim for each crime would be attributed the most blame. These hypotheses were partially supported. First, 
there was general support for the effect of victim characteristics in the aggravated assault crime, such that the younger man victim was blamed more than the younger woman victim and older woman victim, though the rates of victim blaming did not differ between the younger man victim and older man victim. Second, for the sexual assault vignette, younger adults attributed more blame to the younger woman victim and older woman victim than the younger man victim. However, for the pickpocketing and credit card scam crimes, there was no evidence of participants attributing the most blame to the stereotypical victims.

Additionally, it was hypothesized that younger adults would attribute less blame to younger adult victims who were the same gender as them. There was a lack of support for this hypothesis with the aggravated assault vignette, such that younger men and women participants did not differ in the amount of blame attributed to a younger man victim. That younger men participants would attribute less blame to the younger man victim than the other three target victims was also not supported by the findings. With regard to the sexual assault vignette, this expectation was also not supported. Younger men and women participants did not differ in the amount of blame attributed to a younger woman victim of sexual assault, and findings indicated that younger women participants did not attribute the least blame to the younger woman victim when compared to the other three target victims.

Although Study 1 demonstrated that the stereotypical victim does not always garner the most attribution of blame across all crimes, it revealed that victim characteristics do significantly influence the extent to which blame is attributed to victims of aggravated and sexual assault. Additionally, findings from this study highlighted that the type of crime also influences gender differences in the propensity to victim blame. Specifically, younger men participants tended to engage in more victim blaming, regardless of victim characteristics, in the context of 
pickpocketing. However, for aggravated assault, younger men participants engaged in more victim blaming than younger women participants when the older man was the victim. In sum, the results of Study 1 demonstrate the variable effects of victim characteristics, participant characteristics, and crime on people's tendencies to blame the victim.

\section{Study 2}

The purpose of Study 2 was to test the generalizability of the results from Study 1 among a sample of older adults. A significant portion of the victim blaming literature has examined patterns of blame among young or middle-aged adult populations. Thus, less is known about how victim characteristics (i.e., gender and age) affect attributions of blame in older adult populations. As discussed previously, it was expected that the most blame would be attributed to the stereotypical victim for each crime vignette. Furthermore, it was hypothesized that older adults would attribute less blame to older adult victims who are the same gender as them. Specifically, Study 2 addressed six hypotheses:

Hypothesis 1: For the aggravated assault vignette, participants will attribute the most blame to the younger man victim.

Hypothesis 2: For the sexual assault vignette, participants will attribute the most blame to the younger woman victim.

Hypothesis 3: For the pickpocketing vignette, participants will attribute the most blame to the older man victim.

Hypothesis 4: For the credit card scam vignette, participants will attribute the most blame to the older woman victim.

Hypothesis 5: For the pickpocketing vignette, participants who are men will attribute less blame to the older man victim than participants who are women. 
Hypothesis 6: For the credit card scam vignette, participants who are women will attribute less blame to the older woman victim than participants who are men.

Of the very few studies that have examined victim blaming tendencies among older adults, it has been suggested that older adults tend to victim blame more than younger adults (Adams-Price et al., 2004). Thus, an exploratory aim of Study 2 was to compare levels of victim blaming between older adults in Study 2 and younger adults in Study 1.

\section{Method}

\section{Participants}

Based on an a priori power analysis using G*Power, version 3.1 (Faul, Erdfelder, Lang, \& Buchner, 2007), it was determined that a minimum of 277 participants would be needed to detect a small-medium effect size with $\alpha=.05$ and power $=.80$ with a 4 X 2 factorial ANCOVA with two between-subject factors (target victim and participant gender). A total of 487 participants were recruited from Amazon's MTurk. Inclusion/exclusion criteria consisted of: 1) 60 years of age or older and 2) US residence. The age range was selected based on previous work that examined victim blaming in an older adult population (Adams-Price et al., 2004). One hundred thirty nine participants were excluded based on exclusion criteria (e.g., stated age did not align with date of birth). This resulted in a final sample of 348 older adults (51.7\% women; $M_{\text {age }}=65.02$ years, $\mathrm{SD}=4.62$, range: $\left.60-99\right)$. Participants were $81.9 \%$ Caucasian $/$ White, $6.0 \%$ African American/Black, 4.0\% Asian, 3.4\% Hispanic/Latinx, 3.2\% multiethnoracial, 0.9\% who identified as "Other," and 0.6\% Native American.

\section{Procedure}

The procedure for Study 2 was similar that of Study 1 in that participants were invited to complete an online study through MTurk, and they were compensated $\$ 1.00$ for their 
participation. After electronically agreeing to be part of the study, each participant was shown the four crime vignettes in a randomized order. Each vignette was followed by the attributions of blame questions and the crime characteristics questions in a random order. They completed the belief in a just world measure and the demographic questions. In the present study, the BJWS demonstrated acceptable reliability (Cronbach's alpha $=.87 ; M=3.60, S D=.99$ ). Demographic variables were also examined. For ease of interpretation, demographic variables were dichotomized. Namely, $81.9 \%$ of participants were White (vs. not White), $96.6 \%$ identified as heterosexual (vs. not heterosexual), 51.4\% were married (vs. not married), and 91.4\% identified with a religion (vs. did not identify with a religion).

Finally, given that the main vignettes were determined from a pilot sample of young adults, it was important to confirm that the assumptions about the most likely victim for the crimes also hold for older adults. As such, participants were presented with the original nine pilot study vignettes in a random order, and they were asked to identify who they believe would be the most likely victim of each crime. Of note, past studies examining other societal stereotypes (e.g., racial prejudice) have found that the presence of stereotypes do not get weaker across age groups (Stewart, von Hippel, \& Radvansky, 2009). In fact, it has been found that older adults, compared to younger adults, are more likely to make and maintain racial stereotypic inferences (Radvansky, Copeland, \& von Hippel, 2010). This, combined with decades of research demonstrating that stereotypes regarding rape victims are resistant to change (see Suarez \& Gadalla, 2010 for a review), made for the case that societal stereotypes about the most likely victim would hold even among a sample of older adults. 


\section{Results}

Prior to conducting the primary analyses, data were examined for normality, outliers, and missingness. For measures that had skewness and kurtosis greater than one, log transformations were applied. ${ }^{4}$ Analyses were performed with the transformed and non-transformed variables. However, the patterns of results were similar. As such, analyses with the untransformed data are reported for ease of interpretation. Outliers were identified by examining box plots, and values between 1.5 and 3 times the interquartile range were determined to be outliers $(n=24)$. Analyses were conducted with and without outliers, also resulting in patterns of results that were comparable. Thus, outliers were included in the reported analyses. Lastly, frequency analyses indicated that missingness for each measure ranged from $0-0.3 \%$. Missingness was addressed by excluding cases on a pairwise basis.

\section{Vignette Check}

A Pearson Chi-Square analysis was conducted to replicate the pilot study findings regarding whether the most likely victim (younger man, younger woman, older man, or older woman) differed by crime for the older adult sample. The comparison across the nine crimes was significant, $\chi^{2}(24)=1845.71 .25, p<.001$ (see Table 7). Crosstabulations regarding the frequency of victim selection for each crime revealed six crimes for which a significant portion of the participants selected a particular target. Specifically, $64.1 \%$ of all participants selected the younger man as the most likely victim of aggravated assault; $70.1 \%$ of all participants selected the younger woman as the most likely victim of sexual assault; $83.6 \%$ of all participants selected

\footnotetext{
${ }^{4} \log$ transformations were applied to the following variables: victim blaming indices for the sexual assault and credit card scam crimes; severity, seriousness, physical harm, and emotional harm associated with the sexual assault and aggravated assault crimes; likelihood and physical harm associated with the credit card scam and pickpocketing crime.
} 
the younger woman as the most likely victim of intimate partner violence; $54.6 \%$ of all participants selected the older woman as the most likely victim of a credit card scam; and 63.5\% of all participants selected the older woman as the victim of robbery. For the remaining four crimes, there was not a clear victim that the majority of participants selected.

Of note, only $31.6 \%$ of all participants selected the older man as the most likely victim of pickpocketing, compared to $42 \%$ of all participants having selected the older man as the most likely victim of pickpocketing in the pilot study. However, the percentage of older adult participants who selected the older man as the most likely victim of pickpocketing was comparable to the $29.3 \%$ that selected the older man as the most likely victim of pickpocketing in the younger adult sample in Study 1. Subsequent Pearson Chi-Square Goodness-of-Fit analyses demonstrated that selection of the most likely victim of pickpocketing was not equally distributed, $\chi^{2}(3)=26.18, p<.001$. This finding, combined with the initial visual inspection of the crosstabulations, suggested that older adult participants considered the older man and older woman to be the most likely victims of pickpocketing. Taken together, these findings not only suggest that existing stereotypes of an older man victim may not align with a particular type of crime as strongly as the other target victims, but also that existing stereotypes of an older man victim may vary depending on the age of the individual holding the stereotype.

Subsequent Pearson Chi-Square Goodness-of-Fit analyses revealed that selection of the most likely victim of aggravated assault was not equally distributed, $\chi^{2}(3)=285.13, p<.001$. This finding, along with the initial visual inspection of the crosstabulations, corroborate the results of the pilot study indicating that the younger man is considered the stereotypical victim of aggravated assault. In regard to the crimes for which younger and older women are considered as the stereotypical victim, odds ratio computations revealed that the odds of participants choosing 
the younger woman as the victim were 2.18 times higher for the intimate partner violence vignette than the sexual assault vignette, $\chi^{2}(1)=17.85, p<.001$. The odds of participants choosing the older woman as the victim were 1.45 times higher for the robbery vignette than the credit card vignette, $\chi^{2}(1)=5.71, p<.05$. Although the odds ratios did indicate that the younger woman was considered to be the more likely victim of interpersonal violence compared to sexual assault, and that the older woman was considered to be the more likely victim of a robbery compared to a credit card scam, it is important to note that compared to all other crimes, a majority of the older adult participants considered the younger woman to be a stereotypical victim of sexual assault, and the older woman to be a stereotypical victim of the credit card scam.

\section{Covariates}

Means and standard deviations for crime characteristics are presented in Table 8. Bivariate correlations were examined to determine which covariates would be included in the primary analyses (see Table 9). In general, demographic characteristics were not significantly associated with victim blaming measures. However, the dichotomous marital status variable (i.e., married vs. not) was significantly positively associated with victim blaming across three crimes (i.e., sexual assault, credit card scam, and pickpocketing), suggesting that married individuals were more likely to blame the victim than those who were not married. Additionally, a dichotomous sexual orientation variable (i.e., heterosexual vs. not) was significantly negatively associated with victim blaming across three crimes (i.e., sexual assault, aggravated assault, and pickpocketing), such that individuals who identified as heterosexual were less likely to blame the victim than those who did not identify as heterosexual. However, given that the sample was 
largely heterosexual (96.6\%), this demographic variable was excluded from the primary analyses.

Crime characteristics regarding severity, seriousness, and extent to which the victim was physically and emotionally harmed were significantly negatively associated with victim blaming measures for the sexual assault and aggravated assault crimes. These crime characteristics were all significantly positively associated with the victim blaming measure for the credit card scam. The extent to which the victim was physically and emotionally harmed were significantly positively associated with the victim blaming measure for the pickpocketing crime $(p s<.001)$. Given that participants' religious affiliation, the perceived likelihood of the crime, and participants' experience of the respective crime or someone close to them experiencing the respective crime were associated with victim blaming for only one of the crimes, these variables were excluded from the ANCOVAs. Participants' belief in a just world was significantly positively associated with victim blaming for the credit card scam crime. However, it was included as a covariate to keep the analyses across Study 1 and Study 2 consistent. Thus, marital status, crime severity, seriousness, the extents to which the victim was physically and emotionally harmed, and belief in a just world were used as covariates in Study 2.

\section{Victim Blaming}

To determine patterns of victim blaming for the four crimes, the proposed 4 (Victim: Younger Man, Younger Woman, Older Man, or Older Woman) X 2 (Participant Characteristic: Man or Woman) factorial ANCOVA ${ }^{5}$ was conducted for each vignette (i.e., four ANCOVAs

\footnotetext{
${ }^{5}$ An analysis of variance (ANOVA) was also conducted for each crime without covariates. ANOVAs revealed results that were similar to those demonstrated by the ANCOVAs, with 3 exceptions: (1) For the aggravated assault crime, there was still a significant main effect of target victim on victim blaming $\left(F(3,340)=6.99, p=.000, \eta_{\mathrm{p}}{ }^{2}=.06\right)$. Pairwise comparisons indicated that in addition to being blamed less than the younger man victim $(M=3.23, S E=.16)$ and older
} 
total). Victim and Participant Characteristic were entered as between-subjects variables, along with the aforementioned covariates (i.e., marital status, severity, seriousness, physical harm, emotional harm, and belief in a just world). Partial eta-squared $\left(\eta_{\mathrm{p}}{ }^{2}\right)$ was used as a measure of effect size according to Cohen's (1969) convention for small $\left(\eta_{\mathrm{p}}{ }^{2}=0.01\right)$, medium $\left(\eta_{\mathrm{p}}{ }^{2}=0.06\right)$, and large effects $\left(\eta_{\mathrm{p}}{ }^{2}=0.14\right)$. Means and standard errors for victim blaming for each crime by target victim and participant gender are presented in Table 10.

Regarding the aggravated assault crime, there was a significant main effect of target victim on victim blaming $\left(F(3,334)=5.21, p=.002, \eta_{\mathrm{p}}{ }^{2}=.05\right)$. Post hoc analyses revealed that participants blamed the younger man victim more than a younger woman or older woman victim ( $p \mathrm{~s} \leq .05)$. Participants also blamed the older man victim more than the older woman victim ( $p$ $=.008)$. Participants' ratings of victim blaming did not differ between the younger man victim and older man victim $(p=.17)$, the younger woman victim and older man victim $(p=.49)$, or the younger woman victim and older woman victim $(p=.06)$. The main effect of participant gender was not significant for victim blaming tendencies $\left(F(1,334)=2.26, p=.13, \eta_{\mathrm{p}}{ }^{2}=.007\right)$. The Victim $x$ Gender interaction was also not significant for this particular crime $(F(3,333)=.93, p$ $\left.=.43, \eta_{\mathrm{p}}^{2}=.008\right)$.

For the sexual assault crime, the main effect of target victim was not significant for victim blaming tendencies $\left(F(3,333)=.77, p=.51, \eta_{\mathrm{p}}^{2}=.007\right)$. However, there was a significant

man victim $(M=2.88, S E=.15)$, the older woman victim $(M=2.21, S E=.16)$ was blamed less than the younger woman victim $(M=2.68, S E=.16, p=.04)$. (2) There was also a significant main effect of participant gender on victim blaming for the aggravated assault vignette $(F(1,340)$ $\left.=6.97, p=.009, \eta_{\mathrm{p}}{ }^{2}=.02\right)$. Participants who were men $(M=2.96, S E=.11)$ blamed victims more than participants who were women $(M=2.54, S E=.11)$. (3) For the credit card scam, there was a significant effect of gender on victim blaming, $\left(F(1,340)=6.78, p=.01, \eta_{\mathrm{p}}^{2}=.02\right)$. Participants who were men $(M=4.08, S E=.14)$ blamed victims more than participants who were women $(M=3.59, S E=.13)$. 
main effect of participant gender on victim blaming $\left(F(1,333)=9.83, p=.002, \eta_{\mathrm{p}}{ }^{2}=.03\right)$.

Participants who were men blamed victims more than participants who were women. The Victim $\mathrm{x}$ Gender interaction was not significant for the sexual assault crime $(F(3,333)=1.50, p=.21$, $\left.\eta_{\mathrm{p}}^{2}=.01\right)$.

Regarding the pickpocketing crime, there was a significant main effect of target victim on victim blaming $\left(F(3,334)=3.15, p=.003, \eta_{\mathrm{p}}{ }^{2}=.03\right)$. Post hoc analyses revealed that participants exhibited more victim blaming when the victim was a younger man or younger woman, as opposed to an older woman $(p s<.03)$. Participants' rates of victim blaming did not differ between the younger man victim and younger woman victim $(p=.67)$, the younger man victim and older man victim $(p=.21)$, the younger woman victim and older man victim $(p=.08)$, or the older man victim and the older woman victim $(p=.33)$. There was a significant main effect of participant gender on victim blaming $\left(F(1,334)=9.06, p=.003, \eta_{\mathrm{p}}{ }^{2}=.03\right)$. Participants who were men blamed victims more than participants who were women. The Victim x Gender interaction was not significant for this specific crime $\left(F(3,334)=1.37, p=.25, \eta_{\mathrm{p}}{ }^{2}=.01\right)$.

Finally, analyses for the credit card scam crime revealed that the main effects of both target victim $\left(F(3,333)=2.17, p=.09, \eta_{\mathrm{p}}^{2}=.02\right)$ and participant gender $(F(1,333)=1.28, p$ $\left.=.26, \eta_{\mathrm{p}}{ }^{2}=.004\right)$ were not significant for victim blaming tendencies. The Victim $\mathrm{x}$ Gender interaction was also not significant for this specific crime $\left(F(3,333)=1.89, p=.57, \eta_{\mathrm{p}}{ }^{2}=.006\right)$.

\section{Exploratory Analyses}

An exploratory aim of Study 2 was to compare levels of victim blaming between older adults in Study 2 and younger adults in Study 1. In order to investigate this aim, datasets from Study 1 and Study 2 were aggregated, and a 4 (Victim: Younger Man, Younger Woman, Older Man, or Older Woman) X 2 (Participant Characteristic: Younger or Older) factorial ANCOVA 
was conducted for each vignette (i.e., four ANCOVAs total). The aforementioned main effects expected in Studies 1 and 2 were also expected in this exploratory analysis, such that the stereotypical victim for each vignette would be attributed the most responsibility. Furthermore, given a previous study that demonstrated that older adults blame victims more than younger adults (Adams-Price et al., 2004), a main effect based of participant age was expected. Specifically, it was hypothesized that older adults would blame victims more than younger adults.

Regarding the aggravated assault crime, there was a significant main effect of target victim on victim blaming $\left(F(3,685)=6.20, p<.001, \eta_{\mathrm{p}}{ }^{2}=.03\right)$. Post hoc analyses revealed that participants blamed the victim more when the victim was a younger man $(M=3.04, S E=.10)$, as opposed to a younger woman $(M=2.63, S E=.11)$ or older woman $(M=2.43, S E=.11, p \mathrm{~s}$ <.008). Participants also blamed the older man victim $(M=3.04, S E=.10)$ more than the older woman victim $(p=.009)$. Participants' ratings of victim blaming did not differ between the younger man victim and older man victim $(p=.12)$, the younger woman victim and older man victim $(p=.23)$, nor the younger woman victim and older woman victim $(p=.17)$. The main effect of participant age was not significant for victim blaming tendencies $(F(1,685)=.10, p$ $\left.=.75, \eta_{\mathrm{p}}{ }^{2}<.001\right)$. The Victim x Age interaction was not significant for the aggravated assault crime $\left(F(3,685)=.87, p=.46, \eta_{\mathrm{p}}^{2}=.004\right)$.

For the sexual assault crime, analyses revealed that the main effects of both target victim $\left(F(3,684)=2.30, p=.08, \eta_{\mathrm{p}}^{2}=.08\right)$ and participant age $\left(F(1,684)=.70, p=.40, \eta_{\mathrm{p}}{ }^{2}=.001\right)$ were not significant for victim blaming tendencies. The Victim x Age interaction was also not significant for this specific crime $\left(F(3,684)=1.04, p=.37, \eta_{\mathrm{p}}^{2}=.005\right)$. 
Regarding the pickpocketing crime, analyses revealed that the main effects of both target $\operatorname{victim}\left(F(3,685)=1.83, p=.14, \eta_{\mathrm{p}}{ }^{2}=.008\right)$ and participant age $\left(F(1,685)=.46, p=.50, \eta_{\mathrm{p}}{ }^{2}\right.$ $=.001)$ were not significant for victim blaming tendencies. The Victim x Age interaction was also not significant for this specific crime $\left(F(3,685)=1.65, p=.18, \eta_{\mathrm{p}}{ }^{2}=.007\right)$.

Finally, analyses for the credit card scam crime revealed a significant main effect of target victim on victim blaming $\left(F(3,684)=2.81, p=.04, \eta_{\mathrm{p}}{ }^{2}=.01\right)$. Post hoc analyses revealed that participants blamed the victim less when the victim was an older man $(M=3.55, S E=.12)$, as opposed to a younger man $(M=3.88, S E=.12)$, younger woman $(M=4.05, S E=.14)$, or older woman $(M=3.92, S E=.13, p$ s $<.05)$. Participants' ratings of victim blaming did not differ between the younger man victim and younger woman victim $(p=.37)$, the younger man victim and older woman victim $(p=.87)$, or the younger woman victim and older woman victim ( $p$ $=.49$ ). The main effect of participant age was not significant for victim blaming tendencies $\left(F(1,684)=2.13, p=.15, \eta_{\mathrm{p}}^{2}=.003\right)$. The Victim $\mathrm{x}$ Age interaction was not significant for the credit card scam crime $\left(F(3,684)=.58, p=.63, \eta_{\mathrm{p}}^{2}=.003\right)$.

\section{Discussion}

The purpose of Study 2 was to determine the generalizability of the results of Study 1 among a sample of older adults. A series of four hypotheses posited that there would be a main effect of victim characteristics, such that the stereotypical victim for each crime would be attributed the most blame. Overall, these hypotheses were not supported. For the sexual assault, pickpocketing, and credit card scam vignettes, victim blaming did not differ based on victim characteristics. However, for the aggravated assault vignette, there was evidence that participants did indeed blame the younger man victim more than the younger woman victim and older woman victim, but older adults' rates of victim blaming did not differ between the younger man 
victim and older man victim. These patterns were similar to those found among younger adult participants in Study 1. Contrary to expectations, older adults tended to blame a victim of pickpocketing more when the victim was a younger man compared to an older woman. Finally, there was no evidence for the hypotheses that older adults would attribute less blame to older adult victims who were of the same gender.

Interestingly, beyond the six main hypotheses, there was evidence suggesting that participants who were older men blamed victims of sexual assault and pickpocketing more than participants who were older women. As in Study 1, these findings again point to the important role that the type of crime can play in contributing to participant gender differences in victim blaming tendencies.

Of note, exploratory analyses were conducted to compare levels of victim blaming between older adults and younger adults. Although previous researchers (Adams-Price et al., 2004) have found some evidence suggesting that older adults tend to blame victims more than younger adults, results of the present research did not support this pattern across the four crimes.

\section{General Discussion}

The purpose of the present research was to address gaps in the victim blaming literature regarding the consideration of both victims' and participants' intersection of identities, as well as a lack of a focus on crimes other than those related to sexual assault. Specifically, across two studies, we tested the extent to which the intersection of victim characteristics (i.e., gender and age) in combination with participant characteristics (i.e., gender) would affect attributions of blame across four different crimes (i.e., aggravated assault, sexual assault, pickpocketing, and credit card scam). 
Given the well-established tendency for people to make more internal attributions (e.g., attributions of responsibility) when encountering situations that are consistent with stereotypical beliefs (Pettigrew, 1979), it was important to first develop vignettes that aligned with stereotypes regarding societal expectations of the most likely victim for a crime. Doing so allowed for the systematic investigation of the influence of these stereotypes on victim blaming. Findings across the pilot study, Study 1, and Study 2 generally provided consistent evidence for crimes that were associated with all target victims, except the older man. Specifically, the younger man was considered to be the most likely victim of aggravated assault, the younger woman was associated with being the most likely victim of sexual assault, and the older woman was seen as the most likely victim of a credit card scam. Indeed, the older man was not reported to be the most likely victim of any particular crime. One factor that could have contributed to this occurrence is that older age in men is typically associated with greater social resources (Barrett \& von Rohr, 2008), such as perceived power (Maestripieri, Klimczuk, Traficonte, \& Wilson, 2014). Thus, it is possible that for most people, older men do not fit the mold of a "stereotypical victim" because they are associated with greater social security. These findings provide empirical support for the notion that there are certain characteristics associated with a "stereotypical victim" across crimes. As most research on victim blaming has tended to focus on crimes of sexual assault (e.g., Donovan, 2007), it would be beneficial for future studies to replicate these findings and test assumptions regarding the link between other crimes and expectations of the most likely victim. Given that awareness of personal biases represents a critical step in the reduction of prejudice (Plant \& Devine, 2009), this information may be especially beneficial in supplementing efforts to reduce victim blaming. 
Based on attribution theory and its inextricable link to stereotyping (e.g., Power et al., 1996), it was predicted that the most stereotypical victim of each crime would be blamed the most. Although this was not the case in both studies for all of the crimes (i.e., aggravated assault, sexual assault, pickpocketing, and credit card scam), there were some noteworthy patterns that provided partial support for these predictions. For example, with the aggravated assault vignette, the younger man victim was indeed attributed more blame than the younger and older women victims by older participants, although attributions of blame did not differ between the younger man victim and older man victim. This may have been due to lack of a strong stereotype associating an older man victim with a crime. Given that people tend to respond in stereotypeconsistent ways, it is possible that inclusion of the older man victim elicited more ambiguous response patterns, as participants may not have had strong attitudes toward the older man victim to begin with.

Furthermore, despite both the younger adult and older adult participants' endorsement of the association between a younger woman victim and sexual assault, neither group of participants attributed the most blame to the younger woman victim. Older adults did not exhibit any differences in levels of victim blaming across the four target victims, whereas younger adults blamed both the younger woman victim and the older woman victim more than the younger man victim. Of note, younger participants' rates of victim blaming did not differ between the younger woman victim and older man victim, or the younger woman victim and older woman victim. These inconsistent results may have been influenced by the floor effects found with the sexual assault vignette (i.e., very low levels of victim blaming were observed with this particular crime), which may have obstructed the ability to detect true effects. Despite this limitation, these findings broadly illustrate that the intersection of identities (of both the victim and participant) 
can influence tendencies to blame victims of sexual assault. Thus, although previous researchers have found that the gender of a sexual assault victim was not associated with significant differences in victim blaming (McCaul, Veltum, Boyechko, \& Crawford, 1990), it is important to keep in mind that their studies only utilized college student samples and did not manipulate the age of the victim. Consideration of both victim and participant characteristics appear to provide valuable insight into the factors that influence victim blaming.

As for the pickpocketing crime, although victim characteristics were found to influence older adults' attributions of blame toward these victims, older adult participants did not attribute the most blame to the hypothesized older man target victim. Rather, they attributed more blame to a younger man and younger woman than an older woman. Again, this may be explained by a lack of an association between an older man victim and a particular crime. Alternatively, that the older woman victim of aggravated assault and pickpocketing was blamed less than other victims provides support for the notion that within the context of victim blaming, the double jeopardy effect (i.e., when the interplay of sexism and ageism puts older women at a disadvantage compared to other age and gender groups; Krekula, 2007) may not be as relevant, reinforcing the notion that the older woman represents an 'ideal' victim who is free of responsibility (Christie, 1986). However, given that this pattern was not present among the younger adult sample, this interpretation may only apply to the older adult sample in the present research. Indeed, for the younger adult participants, there was no evidence of the older woman being the 'ideal' victim. For instance, the older woman victim was actually attributed more blame than the younger man victim in the sexual assault vignette. Although we expected participants to exhibit stereotype consistent patterns of victim blaming, the present research illustrated the differential influence of victim and participant characteristics, as well as the type of crime on victim blaming. Future 
research efforts should aim to disentangle the complex interplay of these factors and other norms (e.g., rape myth acceptance; Grubb \& Turner, 2012) when investigating differences in victim blaming.

Within the context of defensive attribution (Lerner, 1980; Shaver, 1970), it was hypothesized that participants would attribute the least blame to victims with whom they shared similar identities. Such attributions are proposed to serve as a protective mechanism should the individual ever experience a similar fate. For all crimes, the data generally did not support defensive attributions. The lack of support for defensive attributions may in part be explained by differences in the extent to which the crime vignettes successfully tapped into participants' ideas of stereotypical victims and self-relevance. For example, Study 2 revealed that for older adults, the older woman victim was more strongly associated with a robbery, rather than a credit card scam. Additionally, in Studies 1 and 2, there was a lack of consensus regarding the crime for which an older man might be the most stereotypical victim.

It is interesting to note that the defensive attribution hypothesis did not fully emerge for the sexual assault vignette, especially given that the link between the stereotypical victim (i.e., younger women) and the crime was fairly pronounced. However, as previously discussed, the victim blaming measure for the sexual assault crime was the only outcome measure that was heavily negatively skewed. Thus, there may have been a floor effect that masked the detection of defensive attribution processes. It would be beneficial for future studies to examine if other crimes that are associated with a younger woman as the most likely victim would reveal different patterns of results in the absence of any floor effects.

As for the systematic examination of participant gender, main effects of participant gender emerged for the pickpocketing vignette for both younger and older adult participants, 
such that men blamed victims of pickpocketing more than women. This is one of the first studies to have examined how participant gender is associated with victim blaming in the context of pickpocketing, and although it is unclear why men may have attributed more blame to victims of this crime than women, these findings provide empirical support for the notion that men and women's tendencies to blame the victim vary based on the context of the crime. Relatedly, the main effect of participant gender was absent in the younger adult sample for the sexual assault vignette, yet present in the older adult sample, such that older men participants were more likely to blame victims of sexual assault than older women participants. These findings align with previous studies that have yielded inconsistent results when considering participant gender effects in victim blaming. Some findings have indicated that men blame victims of sexual assault more than women, whereas other studies have demonstrated a lack of a gender difference (see Grubb \& Turner, 2012, for a review). The lack of a gender difference has been explained within the context of attribution theory, such that women may be more likely to blame the victim because they regard the victim as "different" from them (Grubb \& Turner, 2012). However, it is unclear why older men were more likely to blame victims of sexual assault than older women. It would be of interest for future studies to investigate why participant characteristics might matter more in the victim blaming associated with some crimes but not others. The present findings highlight the importance of considering the intersection of participants' identities in conjunction with the crime itself when investigating tendencies to blame victims.

We also tested whether older and younger adults differ in victim blaming tendencies. Previous research has found that older adults blame victims more than younger adults (AdamsPrice et al., 2004). However, there were no significant age differences for any of the crimes in the present study. This may in part be explained by differences between the study design of the 
present research and that of Adams-Price and colleagues' (2004). Specifically, although AdamsPrice and colleagues examined four different vignettes in relation to victim blaming, they consisted of one crime vignette, two vignettes illustrating accidents, and a fourth vignette depicting a fire. As such, it may be that when it comes to crimes in particular (as opposed to accidents or a fire), older adults do not necessarily exhibit more victim blaming than younger adults. Additionally, although these researchers systematically varied details in their vignettes associated with the irresponsibility of the target victim and outcome of the events (e.g., whether the target was more or less irresponsible and whether the outcome was more or less severe), they did not systematically vary victim characteristics, which have been found to influence victim blaming tendencies (Przygotzki \& Mullet, 1997). Finally, Adams-Price and colleagues recruited a community sample of older adults, whereas the present research recruited older adults from MTurk, who were primarily in their 60s. The lack of an age difference in victim blaming could be due to the possibility that older adults on MTurk may resemble younger adults, and as such, the extent to which results may generalize to other groups of older adults are unclear (Barber \& Tan, 2018). Taken all together, the present findings demonstrate that for crime vignettes, victim characteristics are especially important to consider when investigating how participants' age may influence tendencies to blame the victim.

Overall, despite failure to detect consistent patterns of main effects of victim and participant characteristics, it is important to keep in mind that this research is some of the first that has attempted to look at the intersection of these variables across multiple crimes. A significant portion of the victim blaming literature has often focused on crimes related to sexual violence, and the present research attempted to empirically and systematically test the extent to which characteristics that have previously been linked to victim blaming generalize across 
contexts. The variability in our patterns of findings suggest that the context of the crime, even after controlling for crime characteristics (i.e., severity, seriousness, likelihood, emotional and physical harm it brought to the victim) and participants' individual differences (i.e., belief in a just world, marital status), significantly affects the variability of victim blaming tendencies. For example, the credit card scam vignette was not associated with any differences in victim blaming tendencies. This points to the need for studies that seek to identify what exactly it is about the context of the crime that drives certain victim blaming patterns. For instance, it could be that people view certain crimes as more forgiving, or perhaps more emotionally valenced crimes tap into unconscious biases and impressions more readily than less emotionally valenced crimes, which could in turn affect victim blaming tendencies.

Despite the importance of the present findings, some limitations are worth noting. First, given that this study was based upon a self-report method, it is possible that participants did not respond truthfully or responded in a socially desirable way. As such, it would be beneficial for prospective studies to determine the extent to which victim characteristics, participant characteristics, and the type of crime might influence implicit or behavioral indicators of victim blaming. Second, given that some crimes (i.e., pickpocketing) were not as readily linked to a stereotypical victim as other crimes (i.e., sexual assault), future research should seek to elucidate the extent to which certain associations are more salient than others. Third, given that a floor effect was observed with the victim blaming measure for the sexual assault crime, this limited variability may have impeded our ability to detect group differences. As such, it would be beneficial for future studies to also include crimes that produce more variability in victim blaming in order to effectively test for group differences. Finally, there are limitations associated with the utilization of online data collection through MTurk, such as threats to ecological 
validity, decreased control over experimental setting (Kittur, Chi, \& Suh, 2008), samples are not representative of the US population, and the possibility of fraudulent responses (Buhrmester, Talaifar, \& Gosling, 2018). Future studies could be designed to reach a more representative sample and contain more effective fraudulent response checks to better ensure the integrity of the data.

\section{Conclusion}

The present research demonstrated that victim characteristics and participant characteristics contribute to victim blaming tendencies, even after controlling for multiple crime characteristics (e.g., severity of the crime) and individual differences about justice. The extent to which these factors influence victim blaming varied across the type of crime. It was also demonstrated that stereotypical beliefs about the most likely victim for particular crimes exist. However, participants did not exhibit tendencies to actually blame the most likely victim more than other victims. Future research and intervention efforts seeking to understand and reduce victim blaming would benefit from considering the influence of stereotypical beliefs regarding the most likely victim, victim characteristics, type of crime, and participant characteristics. 


\section{References}

Abrams, D., Viki, G. T., Masser, B., \& Bohner, G. (2003). Perceptions of stranger and acquaintance rape: The role of benevolent and hostile sexism in victim blame and rape proclivity. Journal of Personality and Social Psychology, 84, 111-125. doi:10.1037/00223514.84.1.111

Adams-Price, C. E., Dalton III, W. T., \& Sumrall, R. (2004). Victim blaming in young, middleaged, and older adults: Variations on the severity effect. Journal of Adult Development, 11, 289-295. doi:10.1023/B:JADE.0000044532.83720.74

Anderson, I. (1999). Characterological and behavioral blame in conversations about female and male rape. Journal of Language and Social Psychology, 18, 377-394. doi:10.1177/0261927X99018004002

Anderson, I. (2004). Explaining negative rape victim perception: Homophobia and the male rape victim. Current Research in Social Psychology, 10, 43-57. Retrieved from https://uiowa.edu/crisp/

Barrett, A. E., \& Von Rohr, C. (2008). Gendered perceptions of aging: An examination of college students. The International Journal of Aging and Human Development, 67, 359386. doi: 10.2190/AG.67.4.d

Bell, S. T., Kuriloff, P. J., \& Lottes, I. (1994). Understanding attributions of blame in stranger rape and date rape situations: An examination of gender, race, identification, and students' social perceptions of rape victims. Journal of Applied Social Psychology, 24, 1719-1734. doi:10.1111/j.1559-1816.1994.tb01571.x 
Back, S., \& Lips, H. M. (1998). Child sexual abuse: Victim age, victim gender, and observer gender as factors contributing to attributions of responsibility. Child Abuse \& Neglect, 22, 1239-1252. doi:10.1016/S0145-2134(98)00098-2

Barber, S. J., \& Tan, S. C. (2018). Ageism affects the future time perspective of older adults. GeroPsych: The Journal of Gerontopsychology and Geriatric Psychiatry, 31, 115126. doi: 10.1024/1662-9647/a000189

Berinsky, A. J., Huber, G. A., \& Lenz, G. S. (2012). Evaluating online labor markets for experimental research: Amazon.com's Mechanical Turk. Political Analysis, 20, 351-368. doi:10.1093/pan/mpr057

Bieneck, S., \& Krahé, B. (2011). Blaming the victim and exonerating the perpetrator in cases of rape and robbery: Is there a double standard? Journal of Interpersonal Violence, 26, 1785-1797. doi:10.1177/0886260510372945

Bryant, S. A., \& Spencer, G. A. (2003). University students' attitudes about attributing blame in domestic violence. Journal of Family Violence, 18, 369-376. doi:10.1023/A:1026205817132

Braman, A. C., \& Lambert, A. J. (2001). Punishing individuals for their infirmities: Effects of personal responsibility, just-world beliefs, and in-group/out-group status. Journal of Applied Social Psychology, 31, 1096-1109. doi:10.1111/j.1559-1816.2001.tb02664.x

Buss, A. R. (1978). Causes and reasons in attribution theory: A conceptual critique. Journal of Personality and Social Psychology, 36, 1311-1321. doi:10.1037/0022-3514.36.11.1311

Calhoun, L. G., Selby, J. W., Cann, A., \& Keller, G. T. (1978). The effects of victim physical attractiveness and sex of respondent on social reactions to victims of rape. British Journal of Social \& Clinical Psychology, 17, 191-192. doi:10.1111/j.2044-8260.1978.tb00264.x 
Calhoun, L. G., Selby, J. W., \& Warring, L. J. (1976). Social perception of the victim's causal role in rape: An exploratory examination of four factors. Human Relations, 29, 517-526. doi:10.1177/001872677602900602

Callan, M. J., Dawtry, R. J., \& Olson, J. M. (2012). Justice motive effects in ageism: The effects of a victim's age on observer perceptions of injustice and punishment judgments. Journal of Experimental Social Psychology, 48, 1343-1349. doi:10.1016/j.jesp.2012.07.003

Callan, M. J., Kim, H., \& Matthews, W. J. (2015). Age differences in social comparison tendency and personal relative deprivation. Personality and Individual Differences, 87, 196-199. doi:10.1016/j.paid.2015.08.003

Cann, A., Calhoun, L. G., \& Selby, J. W. (1979). Attributing responsibility to the victim of rape: Influence of information regarding past sexual experience. Human Relations, 32, 57-67. doi:10.1177/001872677903200104

Capezza, N. M., \& Arriaga, X. B. (2008). Factors associated with acceptance of psychological aggression against women. Violence Against Women, 14, 612-633. doi:10.1177/107780120831900

Chaikin, A. L., \& Darley, J. M. (1973). Victim or perpetrator? Defensive attribution of responsibility and the need for order and justice. Journal of Personality and Social Psychology, 25, 268. doi:10.1037/h0033948

Christie, N. (1986). The ideal victim. In From Crime Policy to Victim Policy (pp. 17-30). Palgrave Macmillan, London. doi:10.1007/978-1-349-08305-3_2

Cole, E. R. (2009). Intersectionality and research in psychology. American Psychologist, 64, 170-180. doi:10.1037/a0014564 
Cooper, C., Selwood, A., \& Livingston, G. (2008). The prevalence of elder abuse and neglect: a systematic review. Age and Ageing, 37, 151-160. doi:10.1093/ageing/afm194

Crawford, R. (1977). You are dangerous to your health: The ideology and politics of victim blaming. International Journal of Health Services, 7, 663-680. doi:10.2190/YU77-T7B1EN9X-G0PN

Cross, C. (2015). No laughing matter: Blaming the victim of online fraud. International Review of Victimology, 21, 187-204. doi:10.1177/0269758015571471

Cross, C., Parker, M., \& Sansom, D. (2019). Media discourses surrounding 'non-ideal' victims: The case of the Ashley Madison data breach. International Review of Victimology, 25, 53-69. doi:10.1177/0269758017752410

Dalbert, C., Montada, L., \& Schmitt, M. (1987). Belief in a just world: Validation correlates of two scales. Psychologische Beitrage, 29, 596-615. Retrieved from http://www.worldcat.org/title/psychologische-beitrage/oclc/2001918

Dalbert, C., \& Yamauchi, L. A. (1994). Belief in a just world and attitudes toward immigrants and foreign workers: A cultural comparison between Hawaii and Germany. Journal of Applied Social Psychology, 24, 1612-1626. doi:10.1111/j.1559-1816.1994.tb01565.x

Davies, M., Pollard, P., \& Archer, J. (2001). The influence of victim gender and sexual orientation on judgments of the victim in a depicted stranger rape. Violence and Victims, 16, 607-619. Retrieved from https://www.springerpub.com/violence-andvictims.html

Davies, M., Rogers, P., \& Whitelegg, L. (2009). Effects of victim gender, victim sexual orientation, victim response and respondent gender on judgements of blame in a 
hypothetical adolescent rape. Legal and Criminological Psychology, 14, 331-338. doi:10.1348/978185408X386030

Del, G. B., Stermac, L., \& Bainbridge, D. (2005). Comparisons of sexual assault among older and younger women. Journal of Elder Abuse \& Neglect, 17, 1-18. doi:10.1300/J084v17n03_01

Donovan, R. A. (2007). To blame or not to blame: Influences of target race and observer sex on rape blame attribution. Journal of Interpersonal Violence, 22, 722-736. doi:10.1177/0886260507300754

Eigenberg, H., \& Garland, T. (2008). Victim blaming. In Controversies in Victimology (pp. 3348). Routledge.

Faul, F., Erdfelder, E., Lang, A. G., \& Buchner, A. (2007). G* Power 3: A flexible statistical power analysis program for the social, behavioral, and biomedical sciences. Behavior Research Methods, 39, 175-191. doi:10.3758/BF03193146

Franklin, C. A., \& Menaker, T. A. (2015). The impact of observer characteristics on blame assessments of prostituted female youth. Feminist Criminology, 10, 140-164. doi:10.1177/1557085114535234

Frazier, P. A. (1990). Victim attributions and post-rape trauma. Journal of Personality and Social Psychology, 59, 298-304. doi:10.1037/0022-3514.59.2.298

Fulero, S. M., \& DeLara, C. (1976). Rape victims and attributed responsibility: A defensive attribution approach. Victimology, 1, 551-563. Retrieved from https://www.apa.org/pubs/databases/psycinfo

Furnham, A. (2003). Belief in a just world: Research progress over the past decade. Personality and Individual Differences, 34, 795-817. doi:10.1016/S0191-8869(02)00072-7 
Gerdes, E. P., Dammann, E. J., \& Heilig, K. E. (1988). Perceptions of rape victims and assailants: Effects of physical attractiveness, acquaintance, and subject gender. Sex Roles, 19, 141-153. doi:10.1007/BF00290151

Glennon, F., \& Joseph, S. (1993). Just world beliefs, self-esteem, and attitudes towards homosexuals with AIDS. Psychological Reports, 72, 584-586. doi:10.2466/pr0.1993.72.2.584

Gold, A. R., Landerman, P. G., \& Bullock, K. W. (1977). Reactions to victims of crime: Sympathy, defensive attribution, and the just world. Social Behavior and Personality: An International Journal, 5, 295-304. doi:10.2224/sbp.1977.5.2.295

Golding, S., Nadorff, M. R., Winer, E. S., \& Ward, K. C. (2015). Unpacking sleep and suicide in older adults in a combined online sample. Journal of Clinical Sleep Medicine, 11, 13851392. doi:10.5664/jesm.5270

Gordon, M. T., \& Riger, S. (1991). The Female Fear: The Social Cost of Rape. University of Illinois Press.

Grubb, A., \& Harrower, J. (2008). Attribution of blame in cases of rape: An analysis of participant gender, type of rape and perceived similarity to the victim. Aggression and Violent Behavior, 13, 396-405. doi:10.1016/j.avb.2008.06.006

Grubb, A., \& Turner, E. (2012). Attribution of blame in rape cases: A review of the impact of rape myth acceptance, gender role conformity and substance use on victim blaming. Aggression and Violent Behavior, 17, 443-452. doi:10.1016/j.avb.2012.06.002

Hayes, R. M., Lorenz, K., \& Bell, K. A. (2013). Victim blaming others: Rape myth acceptance and the just world belief. Feminist Criminology, 8, 202-220. doi:10.1177/1557085113484788 
Heider, F. (1958). The psychology of interpersonal relations. Hoboken, NJ: John Wiley \& Sons Inc.

Henning, K., Jones, A. R., \& Holdford, R. (2005). “I didn’t do it, but if I did I had a good reason": Minimization, denial, and attributions of blame among male and female domestic violence offenders. Journal of Family Violence, 20, 131-139. doi:10.1007/s10896-005-3647-8

Howard, J. A. (1984). The "normal" victim: The effects of gender stereotypes on reactions to victims. Social Psychology Quarterly, 270-281. doi:10.2307/3033824

Johnson, L. M., Mullick, R., \& Mulford, C. L. (2002). General versus specific victim blaming. The Journal of Social Psychology, 142, 249-263. doi:10.1080/00224540209603898

Kanekar, S., \& Vaz, L. (1988). Attribution of causal and moral responsibility to a victim of rape. Applied Psychology, 37, 35-49. doi:10.1111/j.1464-0597.1988.tb01124.x

Kelley, H. H. (1973). The processes of causal attribution. American Psychologist, 28, 107-128. doi:10.1037/h0034225

Kelly, L. (2010). The (in) credible words of women: False allegations in European rape research. Violence Against Women, 16, 1345-1355. doi:10.1177/1077801210387748

Kleinke, C. L., \& Meyer, C. (1990). Evaluation of rape victim by men and women with high and low belief in a just world. Psychology of Women Quarterly, 14, 343-353. doi:10.1111/j.1471-6402.1990.tb00024.x

Krekula, C. (2007). The intersection of age and gender: Reworking gender theory and social gerontology. Current Sociology, 55, 155-171. doi:10.1177/0011392107073299 
Kristiansen, C. M., \& Giulietti, R. (1990). Perceptions of wife abuse: Effects of gender, attitudes toward women, and just-world beliefs among college students. Psychology of Women Quarterly, 14, 177-189. doi:10.1111/j.1471-6402.1990.tb00013.x

Lachs, M. S., \& Pillemer, K. (2004). Elder abuse. The Lancet, 364, 1263-1272. doi:10.1016/S0140-6736(04)17144-4

Lerner, M. J. (1980). The belief in a just world. In The Belief in a just World (pp. 9-30). Springer, Boston, MA. doi:10.1007/978-1-4899-0448-5_2

Levy, J. A. (1988). Intersections of gender and aging. The Sociological Quarterly, 29, 479-486. doi:10.1111/j.1533-8525.1988.tb01429.x

Luginbuhl, J., \& Mullin, C. (1981). Rape and responsibility: How and how much is the victim blamed? Sex Roles, 7, 547-559. doi:10.1007/BF00288631

Maes, J. (1994). Blaming the victim: Belief in control or belief in justice? Social Justice Research, 7, 69-90. doi:10.1007/BF02333823

Maestripieri, D., Klimczuk, A., Traficonte, D., \& Wilson, C. (2014). A greater decline in female facial attractiveness during middle age reflects women's loss of reproductive value. Frontiers in Psychology, 5, 179. doi: 10.3389/fpsyg.2014.00179

Mason, F., \& Lodrick, Z. (2013). Psychological consequences of sexual assault. Best Practice \& Research Clinical Obstetrics \& Gynaecology, 27, 27-37. doi:10.1016/j.bpobgyn.2012.08.015

Mears, D. P., Reisig, M. D., Scaggs, S., \& Holtfreter, K. (2016). Efforts to reduce consumer fraud victimization among the elderly: The effect of information access on program awareness and contact. Crime \& Delinquency, 62, 1235-1259.

doi: $10.1177 / 0011128714555759$ 
Mendelsohn, B. (1976). Victimology and contemporary society's trends. Victimology, 1, 8-28. Retrieved from https://www.apa.org/pubs/databases/psycinfo

Mendelsohn, B. (1982). Socio-analytic introduction to research in a general victimological and criminological perspective. In H. J. Schneider (Ed.) The victim in international perspective (pp. 59-64). Berlin: De Gruyter.

Meyer, S. (2016). Still blaming the victim of intimate partner violence? Women's narratives of victim desistance and redemption when seeking support. Theoretical Criminology, 20, 75-90. doi:10.1177/1362480615585399

McCaul, K. D., Veltum, L. G., Boyechko, V., \& Crawford, J. J. (1990). Understanding Attributions of Victim Blame for Rape: Sex, Violence, and Foreseeability. Journal of Applied Social Psychology, 20, 1-26. doi:10.1111/j.1559-1816.1990.tb00375.x

Morgan, R. E., \& Mason, B. J. (2014). Crimes against the elderly, 2003-2013. Washington, DC: US Department of Justice, Office of Justice Programs, Bureau of Justice Statistics.

Mulford, C., Lee, M. Y., \& Sapp, S. C. (1996). Victim-blaming and society-blaming scales for social problems. Journal of Applied Social Psychology, 26, 1324-1336. doi:10.1111/j.1559-1816.1996.tb00073.x

Muller, R. T., Caldwell, R. A., \& Hunter, J. E. (1994). Factors predicting the blaming of victims of physical child abuse or rape. Canadian Journal of Behavioural Science/Revue Canadienne des Sciences du Comportement, 26, 259-279. doi:10.1037/0008400X.26.2.259

Niemi, L., \& Young, L. (2016). When and why we see victims as responsible: The impact of ideology on attitudes toward victims. Personality and Social Psychology Bulletin, 42, 1227-1242. doi:10.1177/0146167216653933 
Pagliaro, S., Pacilli, M. G., Giannella, V. A., Giovannelli, I., Spaccatini, F., \& Baldry, A. C. (2018). Legitimizing intimate partner violence: Moral evaluations, attribution of responsibility, and (reduced) helping intentions. Journal of Interpersonal Violence. Advanced online publication doi:10.1177/0886260518760611

Pettigrew, T. F. (1979). The ultimate attribution error: Extending Allport's cognitive analysis of prejudice. Personality and Social Psychology Bulletin, 5, 461-476.

doi:10.1177/014616727900500407

Phelan, J., Link, B. G., Moore, R. E., \& Stueve, A. (1997). The stigma of homelessness: The impact of the label "homeless" on attitudes toward poor persons. Social Psychology Quarterly, 323-337. doi:10.2307/2787093

Plant, E. A., \& Devine, P. G. (2009). The active control of prejudice: Unpacking the intentions guiding control efforts. Journal of Personality and Social Psychology, 96, 640-652. doi:10.1037/a0012960

Power, J. G., Murphy, S. T., \& Coover, G. (1996). Priming prejudice: How stereotypes and counter-stereotypes influence attribution of responsibility and credibility among ingroups and outgroups. Human Communication Research, 23, 36-58. doi:10.1111/j.14682958.1996.tb00386.x

Przygotzki, N., \& Mullet, E. (1997). Moral judgment and aging. European Review of Applied Psychology, 47, 15-21. Retrieved from https://www.researchgate.net/publication/315 339553_Aging_and_moral_judgment

Qi, S. J., Starfelt, L. C., \& White, K. M. (2016). Attributions of responsibility, blame and justifiability to a perpetrator and victim in an acquaintance rape scenario: The influence 
of marijuana intoxication. Journal of Sexual Aggression, 22, 20-35.

doi:10.1080/13552600.2015.1025868

Quraisha, J. B. (2019). “Stripped wallets, ripped hearts” Victims of financial fraud: An analysis beyond financial fraud. People: International Journal of Social Sciences, 4, 1101-1112. doi:10.20319/pijss.2019.43.11011112

Radvansky, G. A., Copeland, D. E., \& von Hippel, W. (2010). Stereotype activation, inhibition, and aging. Journal of Experimental Social Psychology, 46, 51-60.

doi:10.1016/j.jesp.2009.09.010

Reyna, C. (2000). Lazy, dumb, or industrious: When stereotypes convey attribution information in the classroom. Educational Psychology Review, 12, 85-110. doi:10.1023/A:1009037101170

Rogers, P., Josey, N., \& Davies, M. (2007). Victim age, attractiveness and, abuse history as factors in the perception of a hypothetical child sexual abuse case. Journal of Sexual Aggression, 13, 121-137. doi:10.1080/13552600701644835

Sakallı-Uğurlu, N., Yalçın, Z. S., \& Glick, P. (2007). Ambivalent sexism, belief in a just world, and empathy as predictors of Turkish students' attitudes toward rape victims. Sex Roles, 57, 889-895. doi:10.1007/s11199-007-9313-2

Schafer, S. (1968). The victim and his criminal: A study in functional responsibility (Vol. 34). New York: Random House.

Schneider, L. J., Ee, J. S. C., \& Aronson, H. (1994). Effects of victim gender and physical vs. psychological trauma/injury on observers' perceptions of sexual assault and its aftereffects. Sex Roles, 30, 793-808. doi:10.1007/BF01544232 
Shaver, K. G. (1970). Defensive attribution: Effects of severity and relevance on the responsibility assigned for an accident. Journal of Personality and Social Psychology, 14, 101-113. doi:10.1037/h0028777

Shields, S. A. (2008). Gender: An intersectionality perspective. Sex Roles, 59, 301-311. doi:10.1007/s11199-008-9501-8

Sleath, E., \& Bull, R. (2010). Male rape victim and perpetrator blaming. Journal of Interpersonal Violence, 25, 969-988. doi:10.1177/0886260509340534

Spaccatini, F., Pacilli, M. G., Giovannelli, I., Roccato, M., \& Penone, G. (2019). Sexualized victims of stranger harassment and victim blaming: The moderating role of right-wing authoritarianism. Sexuality \& Culture. Advanced online publication. doi:10.1007/s12119019-09592-9

Stephan, W. G. (1977). Stereotyping: The role of ingroup-outgroup differences in causal attribution for behavior. The Journal of Social Psychology, 101, 255-266. doi:10.1080/00224545.1977.9924016

Stewart, B. D., von Hippel, W., \& Radvansky, G. A. (2009). Age, race, and implicit prejudice: Using process dissociation to separate the underlying components. Psychological Science, 20, 164-168. doi:10.1111/j.1467-9280.2009.02274.x

Strömwall, L. A., Alfredsson, H., \& Landström, S. (2013). Blame attributions and rape: Effects of belief in a just world and relationship level. Legal and Criminological Psychology, 18, 254-261. doi:10.1111/j.2044-8333.2012.02044.X

Suarez, E., \& Gadalla, T. M. (2010). Stop blaming the victim: A meta-analysis on rape myths. Journal of Interpersonal Violence, 25, 2010-2035. doi: $10.1177 / 0886260509354503$ 
Sue, D. W. (2004). Whiteness and ethnocentric monoculturalism: Making the "invisible" visible. American Psychologist, 59, 761-769. doi:10.1037/0003-066X.59.8.761

Terrance, C. A., Plumm, K. M., \& Thomas, S. A. (2011). Perceptions of domestic violence in heterosexual relationships: Impact of victim gender and history of response. Partner Abuse, 2, 208-223. doi:10.1891/1946-6560.2.2.208.

Thornton, B., Ryckman, R. M., \& Robbins, M. A. (1982). The relationships of observer characteristics to beliefs in the causal responsibility of victims of sexual assault. Human Relations, 35, 321-330. doi:10.1177/001872678203500404

Thornton, B., \& Ryckman, R. M. (1983). The influence of a rape victim's physical attractiveness on observers' attributions of responsibility. Human Relations, 36, 549-561. doi:10.1177/001872678303600604

Valor-Segura, I., Expósito, F., \& Moya, M. (2011). Victim blaming and exoneration of the perpetrator in domestic violence: The role of beliefs in a just world and ambivalent sexism. The Spanish Journal of Psychology, 14, 195-206. doi:10.5209/rev_SJOP.2011.v14.n1.17

Van der Bruggen, M., \& Grubb, A. (2014). A review of the literature relating to rape victim blaming: An analysis of the impact of observer and victim characteristics on attribution of blame in rape cases. Aggression and Violent Behavior, 19, 523-531. doi:10.1016/j.avb.2014.07.008

Von Hentig, H. (1941). Remarks on the Interaction of Perpetrator and Victim. Journal of Criminal Law and Criminology, 31, 303-309. Retrieved from https://scholarlycommons.law.northwestern.edu/jclc/ 
Von Hentig, H. (1948). The criminal \& his victim: Studies in the sociobiology of crime. New Haven, CT: Yale University Press.

Wakelin, A., \& Long, K. M. (2003). Effects of victim gender and sexuality on attributions of blame to rape victims. Sex Roles, 49, 477-487. doi:10.1023/A:1025876522024

Weber, M., Ziegele, M., \& Schnauber, A. (2013). Blaming the victim: the effects of extraversion and information disclosure on guilt attributions in cyberbullying. Cyberpsychology, Behavior, and Social Networking, 16, 254-259. doi:10.1089/cyber.2012.0328

Whatley, M. A. (1996). Victim characteristics influencing attributions of responsibility to rape victims: A meta-analysis. Aggression and Violent Behavior, 1, 81-95. doi:10.1016/13591789(95)00011-9

Wright, S. E. (1993). Blaming the victim, blaming society or blaming the discipline: Fixing responsibility for poverty and homelessness. Sociological Quarterly, 34, 1-16. doi:10.1111/j.1533-8525.1993.tb00127.x 
Table 1. Frequency of victim selection for each type of crime in the pilot study.

\begin{tabular}{lcccc}
\hline & \multicolumn{4}{c}{ Choice of most likely victim } \\
\cline { 2 - 5 } & $\begin{array}{c}\text { Younger } \\
\text { Man }\end{array}$ & $\begin{array}{c}\text { Younger } \\
\text { Woman }\end{array}$ & $\begin{array}{c}\text { Older } \\
\text { Man }\end{array}$ & $\begin{array}{c}\text { Older } \\
\text { Woman }\end{array}$ \\
\hline Type of crime & & & & \\
Sexual Assault & $1(1.4)$ & $\mathbf{6 6}(\mathbf{9 5 . 7 )}$ & $1(1.4)$ & $1(1.4)$ \\
Credit Card & $12(17.4)$ & $6(8.7)$ & $13(18.8)$ & $\mathbf{3 8} \mathbf{( 5 5 . 1 )}$ \\
Pickpocket & $12(17.4)$ & $10(14.5)$ & $\mathbf{2 9}(\mathbf{4 2})$ & $18(26.1)$ \\
Aggravated Assault & $\mathbf{4 7 ( 6 8 . 1 )}$ & $9(13)$ & $11(15.9)$ & $2(2.9)$ \\
IPV & $2(2.9)$ & $\mathbf{5 9}(\mathbf{8 5 . 5})$ & $1(1.4)$ & $7(10.1)$ \\
Robbery & $5(7.2)$ & $13(18.8)$ & $13(18.8)$ & $\mathbf{3 8}(\mathbf{5 5 . 1})$ \\
Car-Car Accident & $25(36.2)$ & $12(17.4)$ & $17(24.6)$ & $15(21.7)$ \\
Car-Pedestrian Accident & $22(31.9)$ & $15(21.7)$ & $12(17.4)$ & $20(29.0)$ \\
Mugging & $23(33.3)$ & $21(30.4)$ & $11(15.9)$ & $14(20.3)$ \\
\hline
\end{tabular}

Note. For each row, total $n=69$. Data presented as $n(\%)$ for each type of crime. Bolded numbers indicate the crimes for which a majority of participants selected the respective victim. 
Table 2. Mean ratings of all pilot study crime characteristics for each type of crime.

\begin{tabular}{|c|c|c|c|c|c|c|}
\hline & \multicolumn{6}{|c|}{ Type of crime } \\
\hline & Sexual Assault & Credit Card & Pickpocket & $\begin{array}{c}\text { Aggravated } \\
\text { Assault }\end{array}$ & IPV & Robbery \\
\hline \multicolumn{7}{|l|}{ Crime characteristics } \\
\hline Real & $6.12 \mathrm{a}$ & $5.81_{a}$ & $5.88 \mathrm{a}$ & $4.97_{b}$ & $6.45_{c}$ & $5.28 \mathrm{~b}$ \\
\hline Severe & $6.70 \mathrm{a}$ & $4.59 b$ & $4.35 b$ & $6.58 \mathrm{a}$ & $5.58 \mathrm{c}$ & $5.29 \mathrm{c}$ \\
\hline Serious & $6.75 a$ & $4.86_{b}$ & $4.54_{c}$ & $6.74 a$ & $5.70_{\mathrm{d}}$ & $5.38_{\mathrm{d}}$ \\
\hline Likely & $5.57 \mathrm{a}$ & $5.70 \mathrm{ab}$ & $5.43_{\mathrm{a}}$ & $4.48_{c}$ & $6.06_{b}$ & $5.01_{d}$ \\
\hline Victim Responsible & $1.46_{a}$ & $3.83 \mathrm{~b}$ & $2.43 \mathrm{~cd}$ & $2.87 \mathrm{c}$ & $2.30_{\mathrm{d}}$ & $1.84 \mathrm{e}$ \\
\hline Perpetrator Responsible & $6.83_{\mathrm{a}}$ & $6.33 \mathrm{~b}$ & $6.41_{b}$ & $6.48 b$ & $6.32_{b}$ & $6.48_{b}$ \\
\hline Society Responsible & $4.64 a$ & $4.07 \mathrm{bc}$ & $3.86 \mathrm{c}$ & $4.42 \mathrm{ab}$ & $4.46_{\mathrm{ab}}$ & $3.51_{\mathrm{d}}$ \\
\hline Punish & $6.78 \mathrm{a}$ & $5.54_{b}$ & $5.35 b$ & $6.58 \mathrm{a}$ & $5.59_{\mathrm{bc}}$ & $5.86_{c}$ \\
\hline Familiar & 3.72ab & 3.83ab & 3.57a & $2.72_{\mathrm{c}}$ & $4.14_{b}$ & $3.09_{\mathrm{c}}$ \\
\hline Physical Harm & $6.32_{\mathrm{a}}$ & $1.38 b$ & $1.52_{b}$ & $6.67_{\mathrm{c}}$ & $5.06_{d}$ & $2.12_{\mathrm{e}}$ \\
\hline Emotional Harm & $6.84 a$ & $3.29_{b}$ & $3.48 b$ & $5.94_{c}$ & $6.14_{c}$ & $5.23_{\mathrm{d}}$ \\
\hline
\end{tabular}

Note. Subscripts indicate whether cell means in the same row are significantly different from one another based on simple main effects analyses at the $p<.05$ level. Bolded text indicate that two or more of the four main vignettes are not significantly different from one another. 
Table 3. Frequency of victim selection for each type of crime for Study 1.

\begin{tabular}{lcccc}
\hline & \multicolumn{4}{c}{ Choice of most likely victim } \\
\cline { 2 - 5 } & $\begin{array}{c}\text { Younger } \\
\text { Man }\end{array}$ & $\begin{array}{c}\text { Younger } \\
\text { Woman }\end{array}$ & $\begin{array}{c}\text { Older } \\
\text { Man }\end{array}$ & $\begin{array}{c}\text { Older } \\
\text { Woman }\end{array}$ \\
\hline Type of crime & & & & \\
$\quad$ Sexual Assault & $40(11.4)$ & $\mathbf{2 5 4}(\mathbf{7 2 . 2})$ & $21(6.0)$ & $37(10.5)$ \\
Credit Card & $53(15.1)$ & $39(11.1)$ & $88(25.0)$ & $\mathbf{1 7 2 ( 4 8 . 9 )}$ \\
Pickpocket & $84(23.9)$ & $78(22.2)$ & $103(29.3)$ & $87(24.7)$ \\
Aggravated Assault & $\mathbf{2 2 4 ( 6 3 . 6 )}$ & $51(14.5)$ & $47(13.4)$ & $30(8.5)$ \\
IPV & $57(16.2)$ & $\mathbf{2 7 2 ( 7 7 . 3 )}$ & $7(2.0)$ & $16(4.5)$ \\
Robbery & $69(19.6)$ & $80(22.7)$ & $62(17.6)$ & $\mathbf{1 4 1 ( 4 0 . 1 )}$ \\
Car-Car Accident & $132(37.5)$ & $66(18.8)$ & $82(23.3)$ & $72(20.5)$ \\
Car-Pedestrian Accident & $113(32.1)$ & $43(12.2)$ & $97(27.6)$ & $99(28.1)$ \\
Mugging & $119(33.8)$ & $90(25.6)$ & $86(24.4)$ & $57(16.2)$ \\
\hline
\end{tabular}

Note. For each row, total $N=352$. Data presented as $n(\%)$ for each type of crime. Bolded numbers indicate the crimes for which a majority of participants selected the respective victim. 
Table 4. Means and standard deviations for crime characteristics in Study 1

\begin{tabular}{lcccc}
\hline & \multicolumn{4}{c}{ Crime } \\
\cline { 2 - 5 } & $\begin{array}{c}\text { Sexual } \\
\text { Assault }\end{array}$ & $\begin{array}{c}\text { Aggravated } \\
\text { Assault }\end{array}$ & $\begin{array}{c}\text { Credit Card } \\
\text { Scam }\end{array}$ & Pickpocketing \\
\hline Crime & & & & \\
Characteristic & & & & \\
$\quad$ Severe & $6.27(1.21)$ & $6.46(1.03)$ & $4.59(1.40)$ & $4.54(1.36)$ \\
$\quad$ Serious & $6.29(1.23)$ & $6.44(1.04)$ & $4.86(1.40)$ & $4.81(1.35)$ \\
Likelihood & $4.76(1.58)$ & $4.91(1.51)$ & $5.79(1.27)$ & $5.68(1.38)$ \\
Physical Harm & $6.06(1.31)$ & $6.49(1.03)$ & $2.00(1.72)$ & $2.18(1.76)$ \\
$\quad$ Emotional Harm & $6.42(1.04)$ & $5.92(1.35)$ & $4.35(1.73)$ & $4.33(1.73)$ \\
\hline
\end{tabular}

Note. $N=351-352$. 
Table 5. Study 1 correlations between potential covariates and victim blaming for each crime

\begin{tabular}{lcccc}
\hline & \multicolumn{4}{c}{ Victim blaming measure } \\
\cline { 2 - 5 } & $\begin{array}{c}\text { Sexual } \\
\text { Assault }\end{array}$ & $\begin{array}{c}\text { Aggravated } \\
\text { Assault }\end{array}$ & $\begin{array}{c}\text { Credit Card } \\
\text { Scam }\end{array}$ & Pickpocketing \\
\hline Potential covariates & & & & \\
Marital status & $.19 * * *$ & $.19 * * *$ & .09 & $.13 *$ \\
Sexual orientation & -.04 & -.04 & .52 & .25 \\
Race/ethnicity & -.10 & -.06 & $-.16^{* *}$ & -.08 \\
Religious affiliation & .09 & .06 & -.03 & .09 \\
Severe & $-.51 * * *$ & $-.42 * * *$ & $.20 * * *$ & .07 \\
Serious & $-.61 * * *$ & $-.49 * * *$ & $.22 * * *$ & .06 \\
Physical Harm & $-.30 * * *$ & $-.35 * * *$ & $.34 * * *$ & $.62 * * *$ \\
Emotional Harm & $-.50 * * *$ & $-.16^{* * *}$ & $.23 * * *$ & $.19 * * *$ \\
Belief in a Just World & $.15 * *$ & $.12 *$ & $.14 *$ & $.19 * * *$ \\
Experience of crime & .03 & -.06 & -.03 & $-.23 * * *$ \\
Likelihood & .01 & .09 & $-.14 * *$ & $-.19 * * *$
\end{tabular}

Note. $N=351-352$. Demographic variables were dichotomized (i.e., Marital status: $1=$ married, $0=$ not married; Race/ethnicity: $1=$ White, $0=$ not White; Sexual orientation: $1=$ heterosexual, $0=$ not heterosexual; Religious affiliation $=$ identified with a religion, $0=$ did not identify with a religion). Bolded variables indicate the covariates that were included in the present analyses.

${ }^{*} p<0.05 ; * * p<0.01 ; * * * p<0.001$ 
Table 6. Means and standard errors in parentheses for victim blaming indices for each crime split by target victim and participant gender in Study 1

\begin{tabular}{lcccc}
\hline & \multicolumn{4}{c}{ Victim blaming measure } \\
\cline { 2 - 5 } & $\begin{array}{c}\text { Sexual } \\
\text { Assault }\end{array}$ & $\begin{array}{c}\text { Aggravated } \\
\text { Assault }\end{array}$ & $\begin{array}{c}\text { Credit Card } \\
\text { Scam }\end{array}$ & Pickpocketing \\
\hline Target victim & & & & \\
$\quad$ Younger Man & $1.67(.14)$ & $2.99(.14)$ & $4.03(.16)$ & $2.55(.13)$ \\
$\quad$ Younger Woman & $2.20(.13)$ & $2.57(.15)$ & $3.98(.19)$ & $2.51(.13)$ \\
Older Man & $1.98(.13)$ & $2.93(.15)$ & $3.58(.17)$ & $2.42(.13)$ \\
Older Woman & $2.05(.13)$ & $2.52(.15)$ & $3.90(.17)$ & $2.57(.14)$ \\
Participant gender & & & & \\
Man & $2.08(.09)$ & $2.98(.10)$ & $3.91(.13)$ & $2.73(.10)$ \\
Woman & $1.87(.09)$ & $2.52(.10)$ & $3.83(.12)$ & $2.30(.10)$ \\
Mean $(S D)$ & $1.98(1.64)$ & $2.73(1.59)$ & $3.88(1.71)$ & $2.50(1.60)$ \\
$\alpha$ & .95 & .94 & .92 & .93 \\
\hline
\end{tabular}

Note. $N=351-352$. 
Table 7. Frequency of victim selection for each type of crime for Study 2.

\begin{tabular}{lcccc}
\hline & \multicolumn{4}{c}{ Choice of most likely victim } \\
\cline { 2 - 5 } & $\begin{array}{c}\text { Younger } \\
\text { Man }\end{array}$ & $\begin{array}{c}\text { Younger } \\
\text { Woman }\end{array}$ & $\begin{array}{c}\text { Older } \\
\text { Man }\end{array}$ & $\begin{array}{c}\text { Older } \\
\text { Woman }\end{array}$ \\
\hline Type of crime & $29(8.3)$ & $\mathbf{2 4 4 ( \mathbf { 7 0 . 1 } )}$ & $11(3.2)$ & $64(18.4)$ \\
Sexual Assault & $41(11.8)$ & $30(8.6)$ & $87(25.0)$ & $\mathbf{1 9 0}(\mathbf{5 4 . 6})$ \\
Credit Card & $73(21.0)$ & $55(15.8)$ & $110(31.6)$ & $110(31.6)$ \\
Pickpocket & $\mathbf{2 2 3 ( 6 4 . 1 )}$ & $45(12.9)$ & $48(13.8)$ & $32(9.2)$ \\
Aggravated Assault & $23(6.6)$ & $\mathbf{2 9 1 ( 8 3 . 6 )}$ & $8(2.3)$ & $26(7.5)$ \\
IPV & $32(9.2)$ & $38(10.9)$ & $57(16.4)$ & $\mathbf{2 2 1}(\mathbf{6 3 . 5})$ \\
Robbery & $126(36.2)$ & $50(14.4)$ & $96(27.6)$ & $76(21.8)$ \\
Car-Car Accident & $61(17.5)$ & $31(8.9)$ & $128(36.8)$ & $128(36.8)$ \\
Car-Pedestrian Accident & $76(21.8)$ & $45(12.9)$ & $108(31.0)$ & $119(34.2)$ \\
Mugging &
\end{tabular}

Note. For each row, total $N=348$. Data presented as $n(\%)$ for each type of crime. Bolded numbers indicate the crimes for which a majority of participants selected the respective victim. 
Table 8. Means and standard deviations for crime characteristics in Study 2

\begin{tabular}{lcccc}
\hline & \multicolumn{4}{c}{ Victim blaming measure } \\
\cline { 2 - 5 } & $\begin{array}{c}\text { Sexual } \\
\text { Assault }\end{array}$ & $\begin{array}{c}\text { Aggravated } \\
\text { Assault }\end{array}$ & $\begin{array}{c}\text { Credit Card } \\
\text { Scam }\end{array}$ & Pickpocketing \\
\hline Crime & & & & \\
Characteristic & & & & \\
$\quad$ Severe & $6.45(1.06)$ & $6.47(1.03)$ & $5.04(1.49)$ & $4.89(1.41)$ \\
$\quad$ Serious & $6.49(1.00)$ & $6.58(.85)$ & $5.34(1.43)$ & $5.16(1.34)$ \\
Likelihood & $4.63(1.73)$ & $4.93(1.59)$ & $5.81(1.37)$ & $5.71(1.33)$ \\
Physical Harm & $6.15(1.17)$ & $6.37(1.09)$ & $2.15(1.78)$ & $2.12(1.64)$ \\
$\quad$ Emotional Harm & $6.36(1.09)$ & $6.09(1.21)$ & $4.57(1.75)$ & $4.82(1.45)$ \\
\hline
\end{tabular}

Note. $N=347-348$. 
Table 9. Study 2 correlations between potential covariates and victim blaming for each crime

\begin{tabular}{lcccc}
\hline & \multicolumn{4}{c}{ Victim blaming measure } \\
\cline { 2 - 5 } & $\begin{array}{c}\text { Sexual } \\
\text { Assault }\end{array}$ & $\begin{array}{c}\text { Aggravated } \\
\text { Assault }\end{array}$ & $\begin{array}{c}\text { Credit Card } \\
\text { Scam }\end{array}$ & Pickpocketing \\
\hline Potential covariates & & & $.16^{* *}$ & $.12^{*}$ \\
Marital status & $.13 *$ & .10 & -.02 & $-.18^{* * *}$ \\
Sexual orientation & $-.22 * * *$ & $-.14 * *$ & -.04 & -.10 \\
Race/ethnicity & $-.20 * * *$ & -.08 & .04 & .07 \\
Religious affiliation & .05 & .03 & .09 & -.06 \\
Severe & $-.48^{* * *}$ & $-.35^{* * *}$ & .05 & -.07 \\
Serious & $-.54 * * *$ & $-.35 * * *$ & $.29 * * *$ & $.47 * *$ \\
Physical Harm & $-.36 * * *$ & $-.30 * * *$ & $.25 * * *$ & .07 \\
Emotional Harm & $-.47 * * *$ & $-.21 * * *$ & $.11 *$ & .06 \\
Belief in a Just World & -.01 & .09 & -.04 & $-.18^{* * *}$ \\
Experience of crime & .05 & .04 & -.00 & $-.21 * * *$ \\
Likelihood & .02 & .04 & &
\end{tabular}

Note. $N=347-348$. Demographic variables were dichotomized (i.e., Marital status: $1=$ married, $0=$ not married; Race/ethnicity: $1=$ White, $0=$ not White; Sexual orientation: $1=$ heterosexual, $0=$ not heterosexual; Religious affiliation $=$ identified with a religion, $0=$ did not identify with a religion). Bolded variables indicate the covariates that were included in the present analyses.

${ }^{*} p<0.05 ; * * p<0.01 ; * * * p \leq 0.001$ 
Table 10. Means and standard errors in parentheses for victim blaming indices for each crime split by target victim and participant gender in Study 2

\begin{tabular}{lcccc}
\hline & \multicolumn{4}{c}{ Victim blaming measure } \\
\cline { 2 - 5 } & $\begin{array}{c}\text { Sexual } \\
\text { Assault }\end{array}$ & $\begin{array}{c}\text { Aggravated } \\
\text { Assault }\end{array}$ & $\begin{array}{c}\text { Credit Card } \\
\text { Scam }\end{array}$ & Pickpocketing \\
\hline Target victim & & & & \\
Younger Man & $1.72(.12)$ & $3.14(.16)$ & $3.78(.17)$ & $2.56(.14)$ \\
Younger Woman & $1.81(.12)$ & $2.70(.16)$ & $4.13(.20)$ & $2.64(.14)$ \\
Older Man & $1.75(.12)$ & $2.85(.14)$ & $3.47(.18)$ & $2.30(.14)$ \\
Older Woman & $1.95(.11)$ & $2.28(.15)$ & $3.91(.19)$ & $2.11(.13)$ \\
Participant gender & & & & \\
Man & $2.00(.09)$ & $2.86(.11)$ & $3.93(.13)$ & $2.62(.10)$ \\
Woman & $1.61(.08)$ & $2.62(.11)$ & $3.71(.13)$ & $2.19(.10)$ \\
Mean (SD) & $1.81(1.33)$ & $2.74(1.52)$ & $3.80(1.79)$ & $2.40(1.49)$ \\
$\alpha$ & .92 & .93 & .93 & .94 \\
\hline
\end{tabular}

Note. $N=347-348$. 
Figure 1. Study 1 significant interaction between Target Victim and Participant Gender predicting victim blaming of aggravated assault crime. Error bars denote one standard error around the mean.

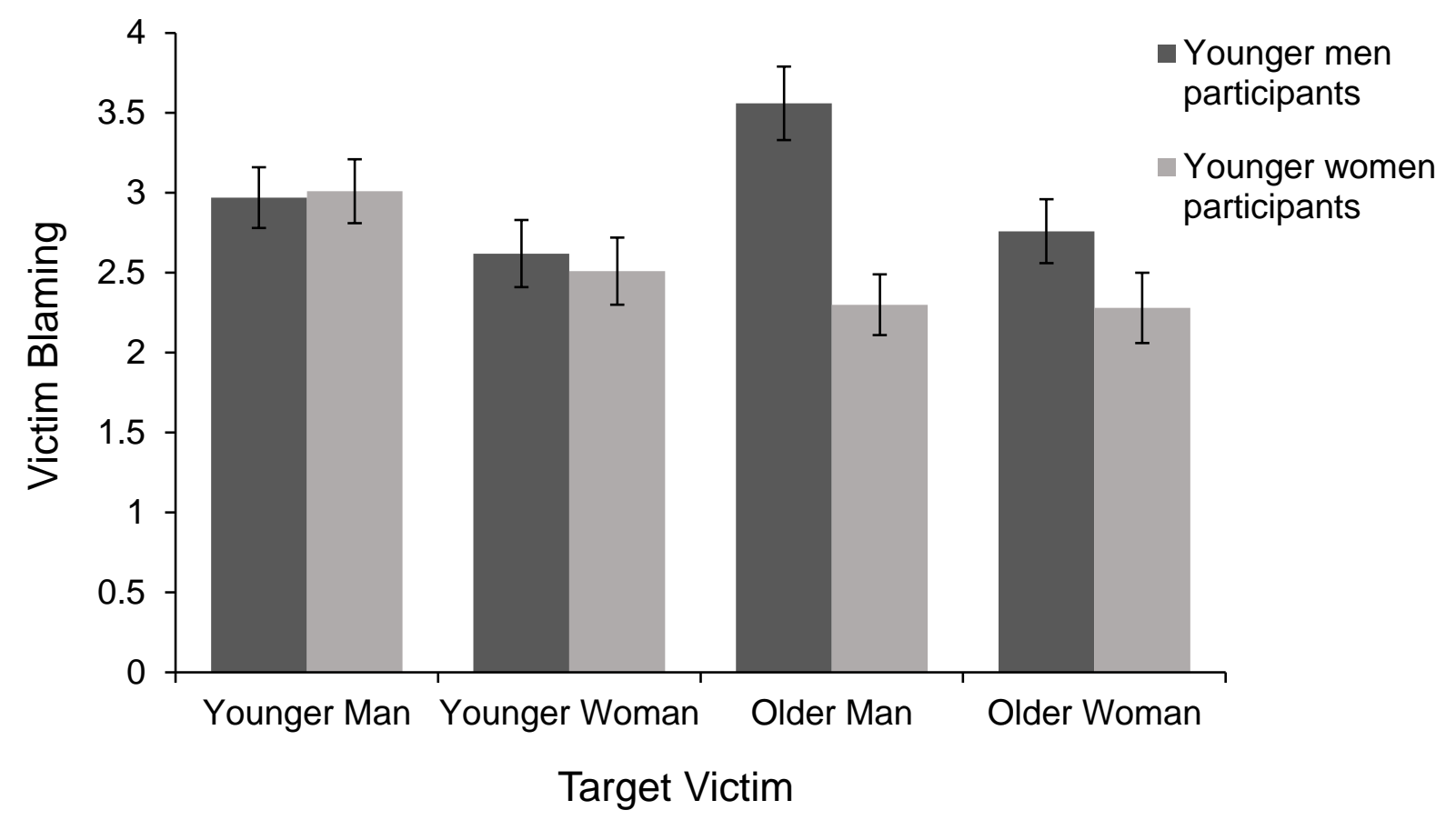




\section{Appendix A}

\section{Pilot Study Vignettes}

1. On January 27, an individual experienced verbal and physical abuse from their partner. Abuse included vulgar name-calling and slapping across the face.

2. On February 3, a robbery occurred on the block of 20th Street. An individual reported that an unidentified person came into their house, verbally threatened them, and started stealing items such as their television and phone.

3. A credit card scam was reported on February 10. An individual reported that an unidentified person posed as a credit card employee over the phone, and asked them for the 3-digit CVV on the back of their card.

4. On February 6, an individual was struck by a car in a crosswalk. The crosswalk does not have flashing lights nor stop signs to alert motorists. The road will be closed for investigation.

5. On January 31, an individual was pickpocketed. At first, they believed their wallet was lost, and then it was reported as stolen when one of their credit cards appeared to be used at a gas station outside of town.

6. On January 29 , an individual was mugged on 7 th Street. The individual was walking down the street toward their car when an unidentified person approached and demanded their wallet and phone. The individual was then struck on the head, and the unidentified person stole their belongings.

7. On February 8, a car accident occurred on Highway 63. An individual was driving south when they were hit by a merging vehicle.

8. An individual was assaulted after leaving a restaurant on February 4. Witnesses observed a dispute between two individuals. One of the individuals pulled out a gun and shot the other before fleeing the scene.

9. An individual was sexually assaulted on February 1 . The individual was approached by an unidentified person when entering their residence. The unidentified person grabbed the individual, forced themself on the individual sexually, and fled the scene. 


\section{Appendix B}

\section{Study 1 and Study 2 Vignettes}

1. A 24-year-old woman was sexually assaulted on February 1 . The younger woman was approached by an unidentified person when entering her residence. The unidentified person grabbed her, forced themself on her sexually, and fled the scene.

2. A 26-year-old man was assaulted after leaving a restaurant on February 4. Witnesses observed a dispute between two individuals. One of the individuals pulled out a gun and shot the younger man before fleeing the scene.

3. A 75-year-old woman reported a credit card scam on February 10. The older woman reported that an unidentified person posed as a credit card employee over the phone, and asked her for the 3-digit CVV on the back of her card.

4. A 77-year-old man was pickpocketed on January 31. At first, the older man believed his wallet was lost, and then it was reported as stolen when one of his credit cards appeared to be used at a gas station outside of town. 
Appendix C

Potential Covariates

Crime Characteristics

Participants indicated their responses across 7-point scales (e.g., ranging from $1-$ Not at all to 7

- Very/Completely/Totally).

1. How severe is this incident?

2. How serious is this incident?

3. Rate the likelihood of this incident.

4. To what extent was the victim emotionally harmed?

5. To what extent was the victim physically harmed? 
The Belief in a Just World Scale (BJWS; Dalbert, Montada, \& Scmitt, 1987)

Below you will find various statements. Most likely, you will strongly agree with some statements, and strongly disagree with others. Sometimes you may feel more neutral. Read each statement carefully and decide to what extent you personally agree or disagree with it. Click the response which corresponds to this judgement.

$\begin{array}{cccccc}\begin{array}{c}\text { Strongly } \\ \text { Agree }\end{array} & \text { Agree } & \begin{array}{c}\text { Slightly } \\ \text { Agree }\end{array} & \begin{array}{c}\text { Slightly } \\ \text { Disagree }\end{array} & \text { Disagree } & \begin{array}{c}\text { Strongly } \\ \text { Disagree }\end{array} \\ 6 & 5 & 4 & 3 & 2 & 1\end{array}$

1. I think basically the world is a just place.

2. I believe that, by and large, people get what they deserve.

3. I am confident that justice always prevails over injustice.

4. I am convinced that in the long run people will be compensated for injustices.

5. I firmly believe that injustices in all areas of life (e.g., professional, family, politics) are the exception rather than the rule.

6. I think people try to be fair when making important decisions. 


\section{Appendix D}

Demographics

Gender:

Man
Woman
Transgender man
Transgender woman
Other

Age:

Marital Status:

Single
Married
Separated
Divorced
Widowed

Ethnicity/Race (check all that apply):

White/Caucasian

Hispanic/Latino(a)

African-American/Black

Asian

Native American

Other - Please list:

Sexual Orientation:

Heterosexual

Gay male

Lesbian

Bisexual

Other

What is your political affiliation?

Republican
Democrat
Libertarian
Independent
Other


What is your religious affiliation:

$\begin{array}{ll} & \text { Christian } \\ & \text { Hindu } \\ & \text { Buddhist } \\ & \text { Not religious }\end{array}$

$\begin{array}{ll} & \text { Muslim } \\ & \text { Jewish } \\ & \text { Atheist } \\ & \text { Agnostic } \\ & \text { Other - Please list: }\end{array}$

How would you characterize your hometown? rural (unincorporated) small town (village or town) suburban (metropolitan area of a large city) small city (population < 30,000) medium-sized city (population 30,000 - 100,000) large city (population > 100,000)

What is your home state?

What is your nationality?

How do you characterize yourself politically? Strongly liberal Liberal Slightly liberal Moderate Slightly conservative Conservative Strongly conservative

Please indicate whether you or someone close to you has ever experienced each of the following:

1. Sexual Assault

2. Aggravated Assault

3. Credit card scam

4. Pickpocketing
Yes No

Yes $\quad$ No

Yes $\quad$ No

Yes No 